\title{
$\begin{array}{ll}\text { Research Square } & \text { Preprints are preliminary reports that have not undergone peer review. } \\ \text { They should not be considered conclusive, used to inform clinical practice, }\end{array}$ or referenced by the media as validated information. \\ Estimating the role of climate internal variability and source of uncertainties in hydrological climate- impact projections
}

\section{Wenjun Cai}

Taiyuan University of Technology

Jia Liu ( $\square$ liujiaiwhr@163.com )

China Institute of Water Resources and Hydropower Research

\section{Xueping Zhu}

Taiyuan University of Technology

\section{Xuehua Zhao}

Taiyuan University of Technology

\section{Research Article}

Keywords: Climate change, GCMs, hydrological climate-impact projections, uncertainties quantified, CIV, ANOVA

Posted Date: December 29th, 2021

DOI: https://doi.org/10.21203/rs.3.rs-1198481/v1

License: (9) This work is licensed under a Creative Commons Attribution 4.0 International License. Read Full License 


\section{Estimating the role of climate internal variability and source of uncertainties in hydrological climate-impact projections}

Wenjun $\mathrm{Cai}^{1} \quad \mathrm{Jia} \mathrm{Liu}^{2, *} \quad$ Xueping Zhu ${ }^{1, *} \quad$ Xuehua Zhao $^{1}$

1 College of Water Resource and Engineering, Taiyuan University of Technology, Taiyuan 030024, China;

2 State Key Laboratory of Simulation and Regulation of Water Cycle in River Basin, China Institute of Water Resources and Hydropower Research

Abstract: Hydrological climate-impact projections in future are limited by large uncertainties from various sources. Therefore, this study aimed to explore and estimate the sources of uncertainties involved in climate changing impacted assessment in a representative watershed of Northeastern China. Moreover, recent researches indicated that the climate internal variability (CIV) plays an important role in various of hydrological climate-impact projections. Six downscaled Global climate models (GCMs) under two emission scenarios and a calibrate Soil and Water Assessment Tool (SWAT) model were used to obtain hydrological projections in future periods. The CIV and signal-to-noise ratio (SNR) are investigated to analyze the the role of internal variability in hydrological projections. The results shows that the internal variability shows a considerable influence on hydrological projections, which need be partitioned and quantified particularly. Moreover, it worth noting the CIV can propagate from precipitation and ET to runoff projections through the hydrological simulation process. In order to partition the CIV and sources of uncertainties, the uncertainty decomposed frameworks based on analysis of variance (ANOVA) are established. The results demonstrate that the CIV and GCMs are the dominate contributors of runoff in rainy season. In contrast, the CIV and SWAT model parameter sets provided obvious uncertainty to runoff in January to May and October to December. The findings of this study advised that the uncertainty is complex in hydrological simulation process hence, it is meaning and necessary to estimate the uncertainty in climate simulation process, the uncertainty analysis results can provide effectively efforts to reduce uncertainty and then give some positive suggestions to stakeholders for adaption countermeasure under climate change. 


\section{Introduction}

Climate change is expected to impact the precipitation and temperature by the end of the $21^{\text {st }}$ century, the changes in precipitation and temperature may substantially effect the regional and global hydrological cycle, quantifying the response of runoff of climate change is directly associated with water resources management.( Zhang et al. 2016; Wang et al. 2018; Vaghef et al. 2019; Anjum et al. 2019; Yuan et al. 2020). Global climate models (GCMs) are primary tools for providing the future climate variables in changing environment, which can be used to simulated the general circulation of the earth's atmosphere, which can provide the credible information from past to future meteorological data (Zhang et al. 2016). Multi-model ensembles consisting of GCMs were used to drive the hydrological models (HMs) to obtain sreamflow and the other hydrological projections. It is become an useful method to estimate the hydrological process response to climate change in various regions of the world (Champagne et al. 2020). However, lots of uncertainties exist in the simulate process of future hydrological climate-impact projections. The different aspects of uncertainty in the model chain can be categorized as: (I) the internal variability of hydrological climate-impact projections simulation; (II) scenarios uncertainty; (III) model uncertainty (Byun et al. 2019; Li et al. 2015; Chen et al. 2016; Ficklin et al. 2016; Zhang et al. 2013; Lee et al. 2016; Nóbrega et al. 2011; Shen et al. 2018).

Scenarios uncertainty is caused by the highly uncertainty trajectory of future socioeconomic development of human societies and the lack of knowledge of future anthropogentic emission of greenhouse gases (GHG) (Lafaysse et al. 2014). The scenarios uncertainty always shows like the different representative concentration pathway (RCP) emission scenarios for future periods.

Model uncertainty is due to the lack of ability to describe the real geophysical process, and embodied in GCM and HM uncertainties. The GCMs uncertainty mainly comes from the the choice of GCMs. Different GCMs always simulated different climate projections under the same emission scenarios. HMs uncertainty due to the model structure and model parameters. The mathematical formulas of hydrological model can portray the rainfall and runoff physical process of basin, because of the lack of ability to describe the real world process, hydrological model are established by incomplete representations of reality (Gupta A and Govindaraju R S 2019), since, it may result in model structure uncertainty. The contribution of parameters uncertainties is significant impacts in the model output, the different parameters may due to the runoff changing in 
opposite directions (Zhang et al. 2019). In addition, parameter uncertainty is relatively to control by some conceptual or empirical parameters and an appropriate calibration method (Wu and Chen 2015). The inappropriate estimation of main parameters may result in non-negligible uncertainty, for this reason, parameters uncertainty has received most attention of previous studies (Nerantzaki et al. 2019).

The climate internal variability (CIV) is the natural variability of the climate system and includes processes intrinstic to the atmosphere, the ocean, the couple ocean-atmosphere system, which is expected to present the natural viability of the regional climate at decadal multi-decadal time scale in the simulation chains (Deser et al. 2012; Lafaysse et al. 2014; Pesce et al. 2019). Due to the chaotic variability of the climate system, the precipitation and temperature simulated by GCMs are influenced by the CIV (Deser et al. 2014). The precipitation and temperature are the important input of hydrological simulation process, hence, the CIV in the climate system are cascading to the hydrological processes (Lafaysse et al. 2014). The uncertainties due to the CIV is the important uncertainty sources in hydrological projections (Hawkins and Sutton 2009). Partitioning and quantifying CIV in a multireplicate multimodel ensemble of hydro-meteorological projections and estimating CIV under different emission scenarios are necessary for provide reliable forecasts and useful decision-making (Lafaysse et al. 2014; Doi and Kim 2020). The internal variability of climate projections has been analyzed by many studies to estimate the uncertainty range of a chosen forced response and obtain a robust detection of climate change effects (Steinschneider et al. 2015; Schindler et al. 2015; Nerantzaki et al. 2020).

Generally, the attribute the hydrological climate-impact projections to CIV is a comparative concept of climate external variability affect by anthropogentic or nature change in external forcing (Doi and Kim 2020; Deser et al. 2012; Thompson et al. 2015). Clearly partitioning CIV and external forcing is necessary for hydrological climate-impact projections uncertainties. Although the some source of uncertainties of hydrological climate-impact projections have been estimated in numerous of researches, the CIV, scenarios, model uncertainties need be equally investigate in future literature. The role of the CIV in hydrological climate-impact projections is also rarely investigate.

To segregate the sources of uncertainties in hydrological climate-impact projections, Bosshard et al. (2013) quantified the uncertainties contributions of an ensemble of hydrological climate 
impact projections by using the analysis of variance (ANOVA) method. The ANOVA technique has fewer assumptions as compared to other uncertainty analysis methods, such as Bayesian methods and Generalized Likelihood Uncertainty Estimation (GULE) (Vaghef et al. 2019). In recently hydrological application, the assessment framework based on ANOVA has been used to investigated the individual and interaction uncertainty from different sources (Chawla et al. 2018; Qi et al. 2016; Kujawa et al. 2020; Keller et al. 2019; Wang et al. 2020). However, the different kinds of uncertainty sources have not been estimated equally in previous researches. They mainly aim on decomposition the GCMs, emission scenarios, downscaling method, hydrological model structure and parameter for simulation process (Kujawa et al. 2020; Shi et al. 2020; Keller et al. 2019). Moreover, to investigate the role of the internal variability in the overall climate change uncertainty can provide more useful information to uncertainty estimating of simulation process and establish more comprehensive framework of uncertainty analysis (Liu et al. 2012; Xue et al. 2014; Yen et al. 2014; Schindler et al. 2015; Steinschneider et al. 2015; Nerantzaki et al. 2020). Therefore, comprehensive and systematical investigating the hydrological climate change impact and estimating different sources of uncertainty is worth and necessary.

The purpose of this manuscript is to estimate the contribution of sources of uncertainty and investigate the role of internal variability in hydrological climate-impact projections in a representative watershed of Northeastern China. In order to obtain a robust detection of climate change effects and give some useful suggestions to practical decision making, the hydrological climate-impact projections in this manuscript contained precipitation, temperature, ET and runoff projections under climate change.

The mainly aim of this study is: (1) to analyze the seasonal changing of precipitation, temperature, ET and runoff projections under climate change; (2) to partition and quantify the source of uncertainty in hydrological climate-impact projections; (3) to investigate the role of internal variability in the hydrological climate-impact projections; (4) to confirm mainly impact source of uncertainty in hydrological simulation process. The uncertainty decomposition framework of this study shows in Fig.1.。 


\section{Hydrological climate- impact projections uncertainty}

Fig.1. Flowchart of the uncertainty decomposition framework of this study

For this purpose, this manuscript combined six GCMs models under two Representative Concentration Pathways (RCPs), which have been based on the fifth phase of the Coupled Model Intercomparison Project (CMIP5). These climate change scenarios were downscaled by the Morphing method, which use an operation of shift or stretch to downscale the hydrological variability (Belcher et al. 2005). A widely used hydrological model SWAT was used to runoff simulation, the SUFI-2 (Abbaspour et al. 2004, 2007) uncertainty approach for capturing the relatively uncertainty of SWAT model parameters. The findings of this research may provide some meaningful suggestions on hydrological climate change impacts and presents a methodology for partitioning uncertainty sources of runoff projections in a representative watershed in Northeastern of China.

\section{Study area and data}

\subsection{Study area}

The Biliu River basin is located in the Northeastern of China spans $39.54^{\circ}$ to $40.35^{\circ} \mathrm{N}$ in latitude and $122.29^{\circ}$ to $122.93^{\circ} \mathrm{E}$ in longitude with an approximate area of $2085 \mathrm{~km}^{2}$ (Fig.2). The Biliu River Reservoir was built in 1975 and the storage of it is $9.34 \times 10^{8} \mathrm{~m}^{3}$. The mainly utility of this reservoir is water supply for nearby big cities and cropland irrigation. Another reservoir, called Yushi Reservoir, which was built in 2001 and located in the upstream of Biliu River, with a

138 storage capacity of $0.89 \times 10^{8} \mathrm{~m}^{3}$ and a drainage area of $313 \mathrm{~km}^{2}$. Because of the reservoir supplies 139 water to the outside of the basin, thus, the impact of Yushi Reservoir should be considered in the 
140 hydrological model. This study area has the characterized of temperate, monsoon marine climate,

141 and with the rainy season from June to September. The mean annual precipitation is $746 \mathrm{~mm}$, the

142 average annual temperature is $8.40^{\circ} \mathrm{C}$ to $10.3^{\circ} \mathrm{C}$, and the maximum and minimum temperatures

143 are $35.8^{\circ} \mathrm{C}$ and $-23.5^{\circ} \mathrm{C}$, respectively.

\section{$144 \quad$ 2.2. Data and climate change scenarios}

145 The historical observed daily precipitation and daily runoff data were available form1978-2004,

146 the monthly precipitation and runoff data were form 1958-2011, which were obtain from the Biliu

147 River Reservoir administration and Hydrology Bureau of Liaoning Province. The DEM, land-use

148 map, and soil type map are obtained from the Data Center for Resources and Environmental

149 Science, Chinese Academy of Sciences.

150 The climate data were used output from six GCMs in CMIP5 under RCP4.5 and RCP8.5

151 emission scenarios: ACCESS1-0, BCC-CSM1.1(m), CESM1-BGC, CESM1-CAM5, CMCC-CM,

152 MPI-ESM-MR (Table1). The climate data were extracted for 1980-2004 period, 2041-2065 period

153 and 2066-2090 period, which defined as reference period, 2050s and 2080s two future period.

154

155

Table 1 Description of CMIP5 climate models and scenarios

\begin{tabular}{lccc}
\hline Climate Models & Country & Resolution & Scenarios \\
\hline ACCESS1.0 & Australia & $1.88^{\circ} \times 2.48^{\circ}$ & RCP4.5, RCP8.5 \\
BCC-CSM1.1(m) & China & $1.13^{\circ} \times 1.13^{\circ}$ & RCP4.5, RCP8.5 \\
CESM1(BGC) & USA & $1.3^{\circ} \times 0.9^{\circ}$ & RCP4.5, RCP8.5 \\
CESM1(CAM5) & USA & $1.3^{\circ} \times 0.9^{\circ}$ & RCP4.5, RCP8.5 \\
CMCC-CM & Italy & $0.75^{\circ} \times 0.75^{\circ}$ & RCP4.5, RCP8.5 \\
MPI-ESM-MR & Germany & $1.88^{\circ} \times 1.88^{\circ}$ & RCP4.5, RCP8.5 \\
\hline
\end{tabular}




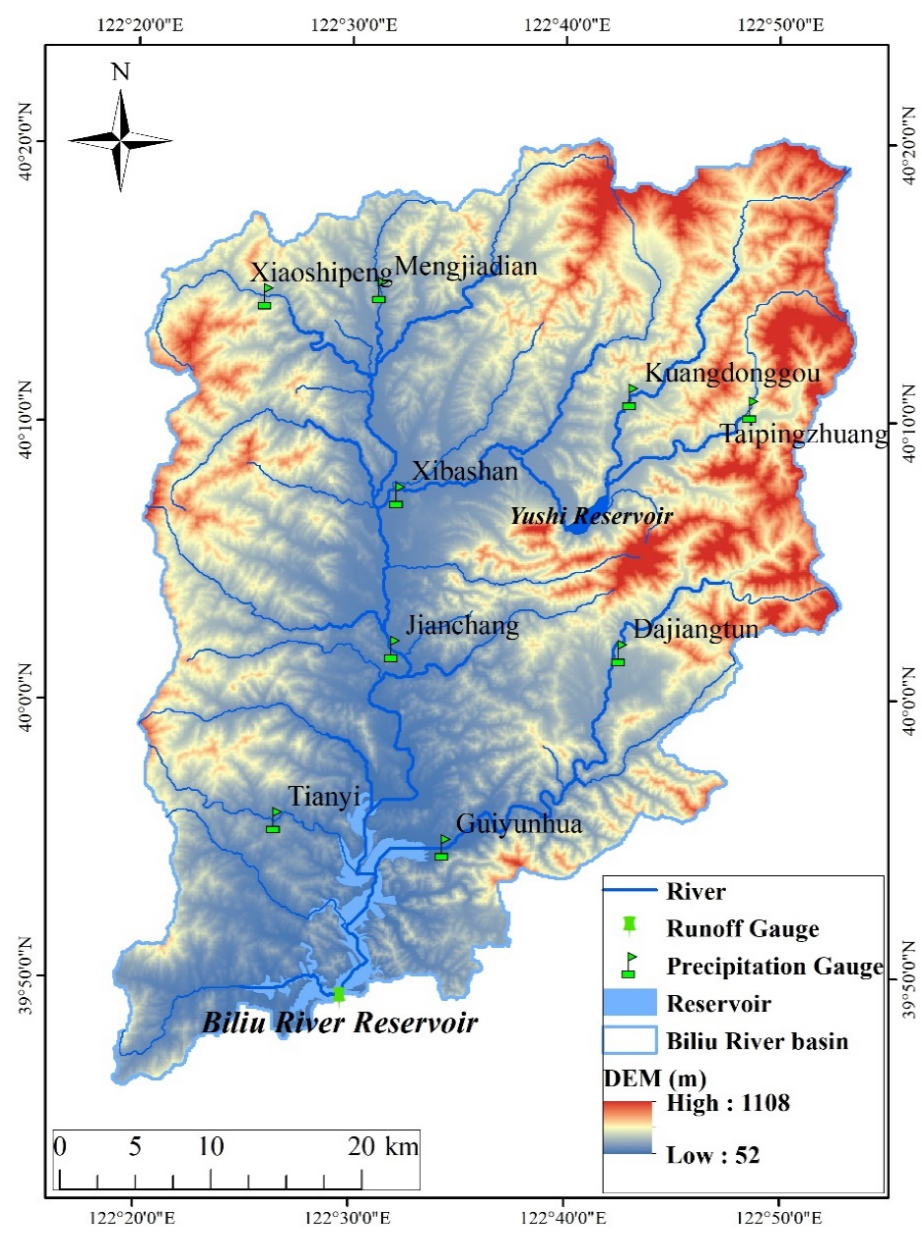

157

Fig.2. The location of precipitation gauge, runoff gauge, river, boundaries in Biliu River basin.

\section{Methodology}

\subsection{Hydrological modeling and parameter uncertainty assessment}

The SWAT 2012 is used to simulate runoff in this study. SWAT is a physically based water-scale model which is widely used in investigating hydrological processes around the world (Wang et al. 2020). The model divided the watershed into hydrologic response units (HRUs), each of these HRUs based on a unique combination of soil, land use and slope characteristics (Nie et al. 2011). Recently, the model has been developed to estimate the climate change impact on hydrological regimes in the predict conditions over long periods of future. The SWAT-CUP software was utilized for calibration and uncertainty assessment of parameters (Abbaspour et al. 2007). SUFI2 algorithm was chosen to calibrate and validate the parameters in the SWAT-CUP (Abbaspour et al. 2004). In order to account for the parameter uncertainty of the model, this manuscript used Latin hypercube sampling (LHS) to generated hydrological model parameter sets. The Nash-Sutcliffe 
|Re| below 10.

178

\subsection{Climate change scenario and downscaling method}

The CMIP5 have provide future climate database and widely around the world (Kujawa et al. 2020; Zhu et al. 2018; Shi et al. 2020). Six GCMs from CMIP5 were selected to represent the future climate scenarios under RCP4.5 and RCP8.5 emission scenarios. SWAT model was driven by six GCMs and two emission scenarios, for a total of 12 ensemble scenario members under 2050s and 2080s.

Because of the simper and easily using merits (Abbaspour et al. 2004; Zhu et al. 2018; Chen et al. 2010), this manuscript adopts Morphing approach to remove biased from the original GCMs climate projections, this method involves a shift, a linear stretch (scaling factor), and a combination of shift and a stretch (Belcher et al. 2005). The downscaled precipitation and temperature are calculated by Morphing and shows acceptable performance in the study watersheds more details of the downscaling process were shown in Zhu et al. (2018).

\subsection{Method of the CIV estimation}

In order to investigate the role of the CIV in hydrological climate-impact projections, the externally forced and internal variability need be partitioned and quantified particularly. Generally, the internal variability is quantified by the "detrend" and "differenced" method, the external forcing is subtracted from the hydrological variable series, and then the fluctuations of the variables are regarded as internal variability (Kim et al. 2018). The average of a large number ensemble members can average out the internal variability, and then the signal remaining is the response of external forcing (Frankcombe et al. 2015). Hence, the internal variability can be obtained by subtracting the model-mean from each ensemble member (Frankcombe et al. 2015). The standard deviation of the ensemble variable or the residual to quantify the internal variability is the robust method has been applied in many previous publications (Yu et al. 2020; Maher et al. 


$$
C I V=\frac{1}{N} \sum_{i=1}^{N}\left(\sqrt{\frac{1}{T-1} \sum_{j=1}^{T}\left(H c_{i, j}-\overline{H c_{i, j}}\right)^{2}}\right)
$$

Where $i$ and $j$ is the ensemble number and the individual year; $\mathrm{N}$ and $\mathrm{T}$ are the total number of ensemble numbers and years, respectively; $\mathrm{HC}$ is the month time series of hydrological climate-impact variables.

The key of estimating CIV is partitioning the external forcing from the hydrological series, and the standard deviation of the given hydrological climate-impact projections is calculated as internal variability (Evin et al. 2019). The signal-to-noise ratio (SNR) always be used to quantify the relative contributions of internal variability and external forcing (Deser et al. 2014). The SNR can provide useful information to investigate the magnitude of external forcing and internal variability of hydrological climate-impact projections under future climate change. The model-mean of each ensemble is used as signal, and the ensemble average of sum of the squared difference between each member and ensemble mean is defined as noise (Evin et al. 2019). The SNR is defined signal divided by noise.

$$
\begin{gathered}
\text { nosie }=\sqrt{\frac{1}{T(N-1)} \sum_{j=1}^{T} \sum_{i=1}^{N}\left(H c_{i j}-\overline{H c_{j}}\right)^{2}} \\
\overline{H c_{j}}=\frac{1}{N} \sum_{i=1}^{N} H c_{i j}
\end{gathered}
$$

\subsection{Source of uncertainties decomposition}

(1) The hydrological response to climate change

For any hydrological projections obtained from hydrological simulation process for the $\mathrm{i}^{\text {th }}$ member of and time $\mathrm{j}^{\text {th }}$, the raw hydrological projections can be decomposed by hydrological response to climate change and internal vairability (Evin et al. 2019; Hingray et al. 2019). The raw hydrological projections $Y_{i, j}$ under climate change can be express as Eq. (4).

$$
Y_{i, j}=\varphi_{i, j}+\eta_{i, j}
$$

224 Where $\varphi_{\mathrm{i}, \mathrm{j}}$ is the hydrological response to climate change; $\eta_{\mathrm{i}, \mathrm{j}}$ is the deviation from the hydrological response obtained with $\mathrm{i}^{\text {th }}$ member of and time $\mathrm{j}^{\text {th. }}$ which can also be express as internal variability. 

as Eq. (5):

$$
\varphi_{i, j}=\mu+\alpha_{h}+\beta_{k}+\gamma_{l}+\xi_{h, k, l}
$$

Where $\mu$ is the overall mean of hydrological response to climate change; $\alpha_{\mathrm{h}}$ is the effect contributed by hydrological model parameters; $\beta_{\mathrm{k}}$ is the effect contribute by GCMs; $\gamma_{1}$ is the effect contribute emission scenarios; $\xi_{\mathrm{h}, \mathrm{k}, \mathrm{l}}$ is the interaction terms of the model.

(3) The different components of the total uncertainty

On the base of the above expression of the raw hydrological response from GCM/emission scenarios, the overall variance of the hydrological projections $\operatorname{Var}\left[Y_{h, k, l}\right]$ as flowing:

$$
\operatorname{Var}\left[Y_{h, k, l}\right]=\operatorname{Var}\left[\varphi_{h, k, l}\right]+\operatorname{Var}\left[\eta_{h, j, k}\right]
$$

Where $\operatorname{Var}\left[\varphi_{h, k, l}\right]$ is the total uncertainty in hydrological response, $\operatorname{Var}\left\lfloor\eta_{h, j, k}\right\rfloor$ is the uncertainty of internal variability of hydrological projections.

$$
\operatorname{Var}\left\lfloor\varphi_{h, j, k}\right\rfloor=\operatorname{Var}\left[\alpha_{h}\right]+\operatorname{Var}\left\lfloor\beta_{j}\right\rfloor+\operatorname{Var}\left[\gamma_{k}\right]+\operatorname{Var}\left[\xi_{h, j, k}\right\rfloor
$$

Where $\operatorname{Var}\left[\alpha_{h}\right]$ is the variance of SWAT model parameters effects; $\left.\operatorname{Var} \mid \beta_{j}\right\rfloor$ is the variance of GCMs model effect; $\operatorname{Var}\left[\gamma_{k}\right]$ is the variance of the emission scenarios; $\operatorname{Var}\left[\xi_{h, j, k}\right\rfloor$ is the variance of the interaction effects.

(4) Source of uncertainties quantifying

This manuscript constructs a three-way ANOVA framework to decomposition the different uncertainties contribution, this technology has ability to partition the total observed variance into different sources, and then quantify the contribution of different sources to total variance (Wang et al. 2018; Aryal et al. 2017).

It based on a biased variance estimator that underestimates the variance when the sample size is small. In order to diminish the bias effects caused by the different number of levels of the uncertainty factors, Bosshard et al. (2013) proposed a subsampling method was applied in this manuscript. This subsampling technology selected two samples from the large sample sets, and then a new sample can be generated for ANOVA. This manuscript selects two SWAT parameters sets out of the 100 sets, the superscript $j$ was replaced by $g(h, i)$, which is $2 \times 4950$ matrix as following: 


$$
g=\left(\begin{array}{ccccccccc}
1 & 1 & \cdots & 1 & 2 & 2 & \cdots 98 & 98 & 99 \\
2 & 3 & \cdots & 100 & 3 & 4 & \cdots 99 & 100 & 100
\end{array}\right)
$$

Based on the ANOVA theory and the form of Eq. (6) and Eq. (7), the ANOVA model can be expressed as Eq. (9). It is composed by the mean effects of SWAT model parameters $\left(\alpha_{\mathrm{h}}\right)$, GCMs model $\left(\beta_{\mathrm{k}}\right)$, emission scenarios $\left(\gamma_{1}\right)$, internal variability $\left(\eta_{\mathrm{h}, \mathrm{j}, 1}\right)$ and interaction effects $\left(\xi_{\mathrm{h}, \mathrm{j}, 1}\right)$. The mean effects can be computer as the deviation of each factors mean value and the global mean $M^{g(-, j),-,-}$

$$
M^{g(h, j), k, l}-M^{g(-, j),-,-}=\alpha_{h}+\beta_{j}+\gamma_{l}+\eta_{h, j, l}+\xi_{h, j, l}
$$

In the ANOVA model, the total variance of the hydrological variable $M^{g(h, j), k, l}$ is expressed as the total sum of squares (SST), and it can decompose into individual variance of each effect:

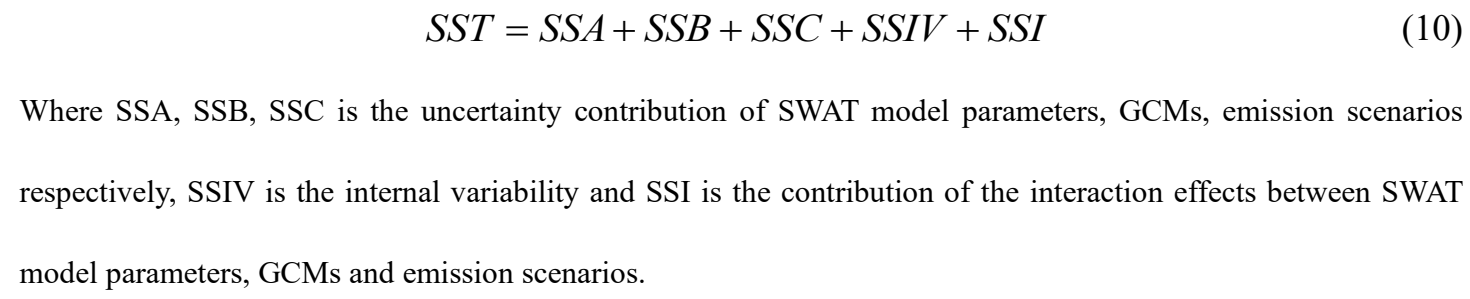$$
S S T=S S A+S S B+S S C+S S I V+S S I
$$

Where SSA, SSB, SSC is the uncertainty contribution of SWAT model parameters, GCMs, emission scenarios respectively, SSIV is the internal variability and SSI is the contribution of the interaction effects between SWAT model parameters, GCMs and emission scenarios.

By this approach, the intercomparisons among the uncertainty contribution of SWAT model parameter, GCMs, emission scenarios, internal variability and the interaction effects are not affected by the different sampling number.

\section{Results}

\subsection{Hydrological model parameters calibrated and uncertainty}

The SWAT model is constructed based on the historical daily meteorological data and spatial geographic data of the study basin. Before being used to predict the future runoff, the hydrological model parameters need to be calibrated and validated. This study divided the calibration period (1982 1996) and validation period (1997 2011) based on the precipitation and runoff changing trends. The simulated data from the SWAT was compared with the historical observed data to ensure its reliability. Three metrics $E_{N S}, R_{e}$, and $R^{2}$ are been used to estimate the model performance during calibrated and validated period. More details about the calibration and validation were introduced in (Zhu et al. 2018). The SUFI2 method is used to calibrate the parameters for the 1982-2011 period runoff in study area. The parameters setting was shown in 
Table 2 The selected SWAT model parameters

\begin{tabular}{llcc}
\hline Parameter & \multicolumn{1}{c}{ Definition } & Min & Max \\
\hline CN2 & Initial SCS runoff curve number for moisture condition & 0.75 & 1.25 \\
SURLAG & Surface runoff lag coefficient & 1.00 & 23.98 \\
LAT_TTIME & Lateral flow converge coefficient & 0.01 & 179.92 \\
ESCO & Soil evaporation compensation factor & 0.01 & 1.00 \\
GW_DELAY & The delay time & 0.37 & 500.00 \\
ALPHA_BF & Baseflow alpha factors (days) & 0.00 & 1.00 \\
GWQMN & Threshold depth of water in the shallow aquifer required for return & & \\
SFTMP & flow to occur & 0.41 & 499.72 \\
SMFMX & Snowfall temperature & -5.00 & 5.00 \\
TIMP & Melt factor for snow & 1.50 & 8.00 \\
\hline
\end{tabular}

The SUFI2 is used as a parameter uncertainty estimate method for reference period in the study basin. For final ensemble of the 100 parameter sets generate by the LHS, and then these parameter sets are put in the SWAT model to generate 100 behavioral simulations which are performance in Fig. 3 with the help of box plots. Each box represents 100 behavioral simulations which outputs by the calibrated SWAT model. The length of the box plots denotes the runoff changes range from

291100 simulations corresponding to one specific month. The differences between two boxes shows 292 the parameters effect are quite differently for one given month. It can be seen in Fig. 3 that the month runoff change range due to SWAT model parameter sets are relatively larger in June to

294 September. As the June to September is the flooding season of the watershed, the uncertainty of runoff may play important role in flood control and management. Hence, the uncertainty contribution of the SWAT model parameter sets need be quantified. 


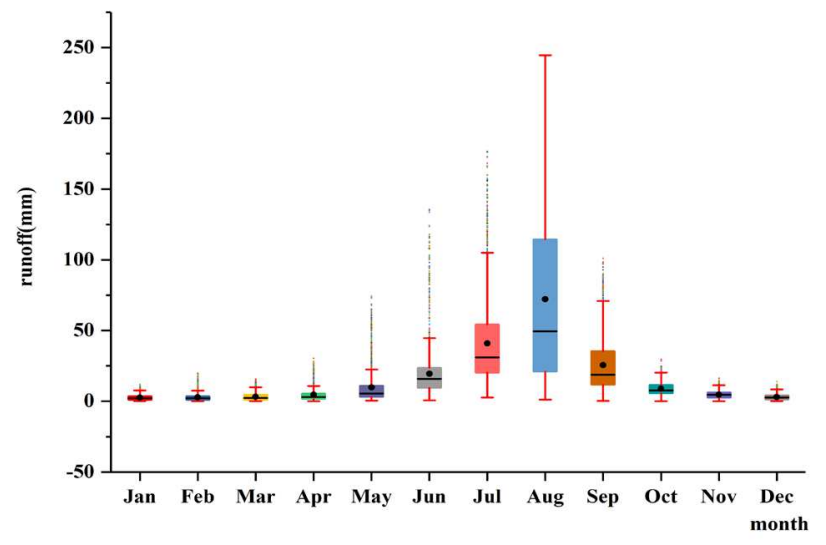

Fig.3. The SWAT model parameters uncertainty of the reference periods.

\subsection{Estimating the uncertainties of hydrological climate-impact projections under climate change \\ 4.2.1 Changes in precipitation projections}

The precipitation projections in 2050s and 2080s are compared with the reference period and demonstrated in Fig.4. It can be seen that the lots of scenario members performance a marked increase trend in 2050s and 2080s, however, several members show a decreased trend.

Take 2050s summer for example, all of the precipitation projections show an increased trend except for CMCC-CM and MPI-ESM-MR performance an decreased trend under RCP8.5 scenarios, the precipitation changing interval is from $54.13 \%$ increase to $-21.2 \%$ decrease. The uncertainty of precipitation projections is significant in the 2080s winter, which changes from $-19.79 \%$ to $95.95 \%$. In contrast, the changing rang of spring and autumn are relatively small, among the two future periods, the uncertainty range of spring is from $31.2 \%$ to $-21.27 \%$ in $2050 \mathrm{~s}$, and the range from $1.71 \%$ to $41.18 \%$ in 2080 s autumn. Compared to the other seasons, the change range of spring is smallest in 2080 s.

The precipitation projections of different GCMs in the same emission scenarios and periods displays a obvious changing range. It can be noted that the precipitation projections have non-negligible uncertainty in future. This uncertainty of precipitation propagates through the hydrological model and is amplified in the runoff outputs. Hence, the precipitation uncertainty under climate change need be investigated previously. 
320

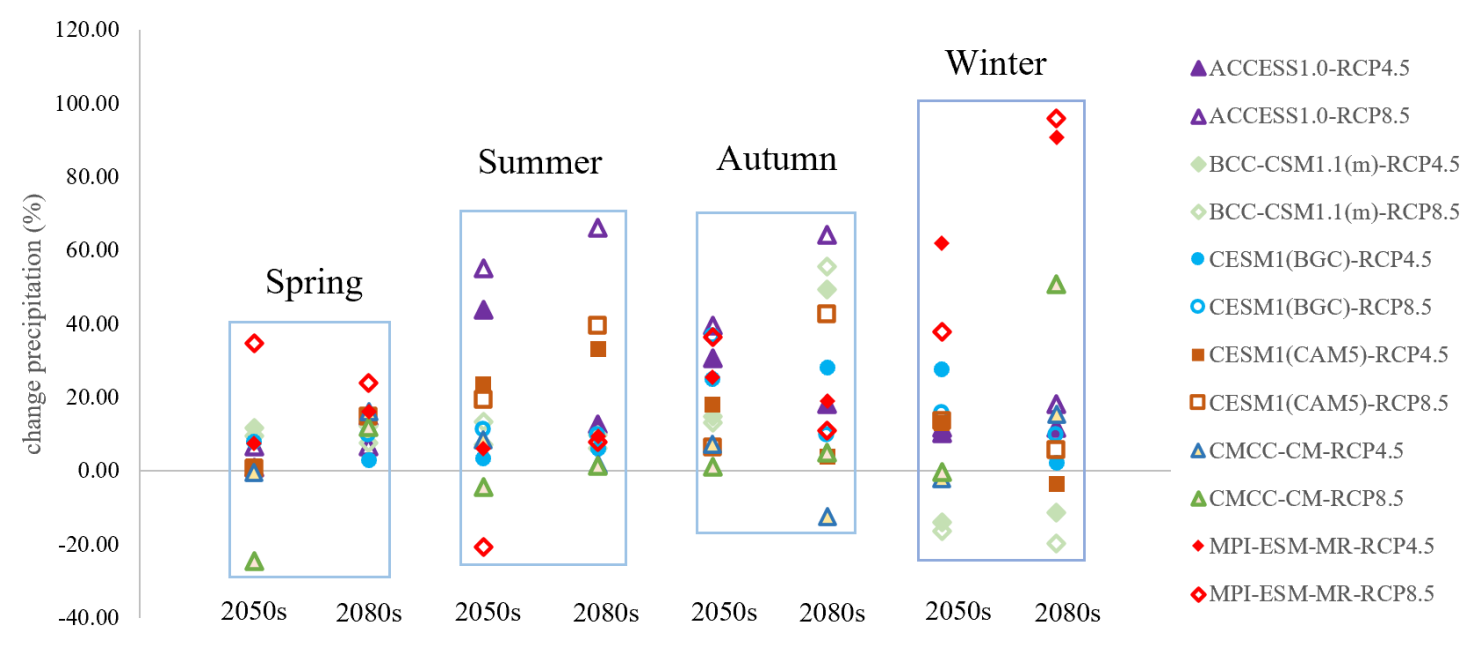

Fig.4. The uncertainty range of the precipitation change is shown for the four seasons.

\subsubsection{Change in temperature projections}

The box chart of Fig.5a and Fig.5b shows the maximum and minimum temperature projections ( $\mathrm{T}_{\max }$ and $\mathrm{T}_{\min }$ ) compared to the reference period, the temperature projections show a univocal increased trend for each scenarios member. Specifically, in the 2050s period, the mean temperature increases of $1.95{ }^{\circ} \mathrm{C}$ under RCP4.5 and $2.73{ }^{\circ} \mathrm{C}$ under RCP8.5, while increase of $2.73{ }^{\circ} \mathrm{C}$ under RCP4.5 and $4.20^{\circ} \mathrm{C}$ under RCP8.5 in the 2080s period. Moreover, the increase ranges of the $T_{\max }$ are larger in summer and autumn than the other season. The summer mean of $\mathrm{T}_{\max }$ increases by $1.84^{\circ} \mathrm{C}$ and $2.52^{\circ} \mathrm{C}$ in two future periods under RCP4.5. Again, the increase range of $T_{\max }$ also significant under $\mathrm{RCP} 8.5$, where the increase of mean $\mathrm{T}_{\max }$ were $2.61^{\circ} \mathrm{C}$ in $2050 \mathrm{~s}$ summer and $4.17^{\circ} \mathrm{C}$ in $2080 \mathrm{~s}$ autumn. The changing trend of $\mathrm{T}_{\min }$ shows a similar increasing trend in two future periods, and the ranges of increase of mean $T_{\min }$ are all above $4.0^{\circ} \mathrm{C}$ in summer, autumn and winter under RCP8.5.

From the $\mathrm{T}_{\max }$ and $\mathrm{T}_{\min }$ changing result in 2050s and 2080s under two emission scenarios, it can be found that the increase temperature became larger as the time increased into future period, and increased range is larger under RCP8.5 than RCP4.5. It can be also obtained that the uncertainty of temperature is marked in future among different scenario members, the mainly uncertainties source need be quantified and estimated. 

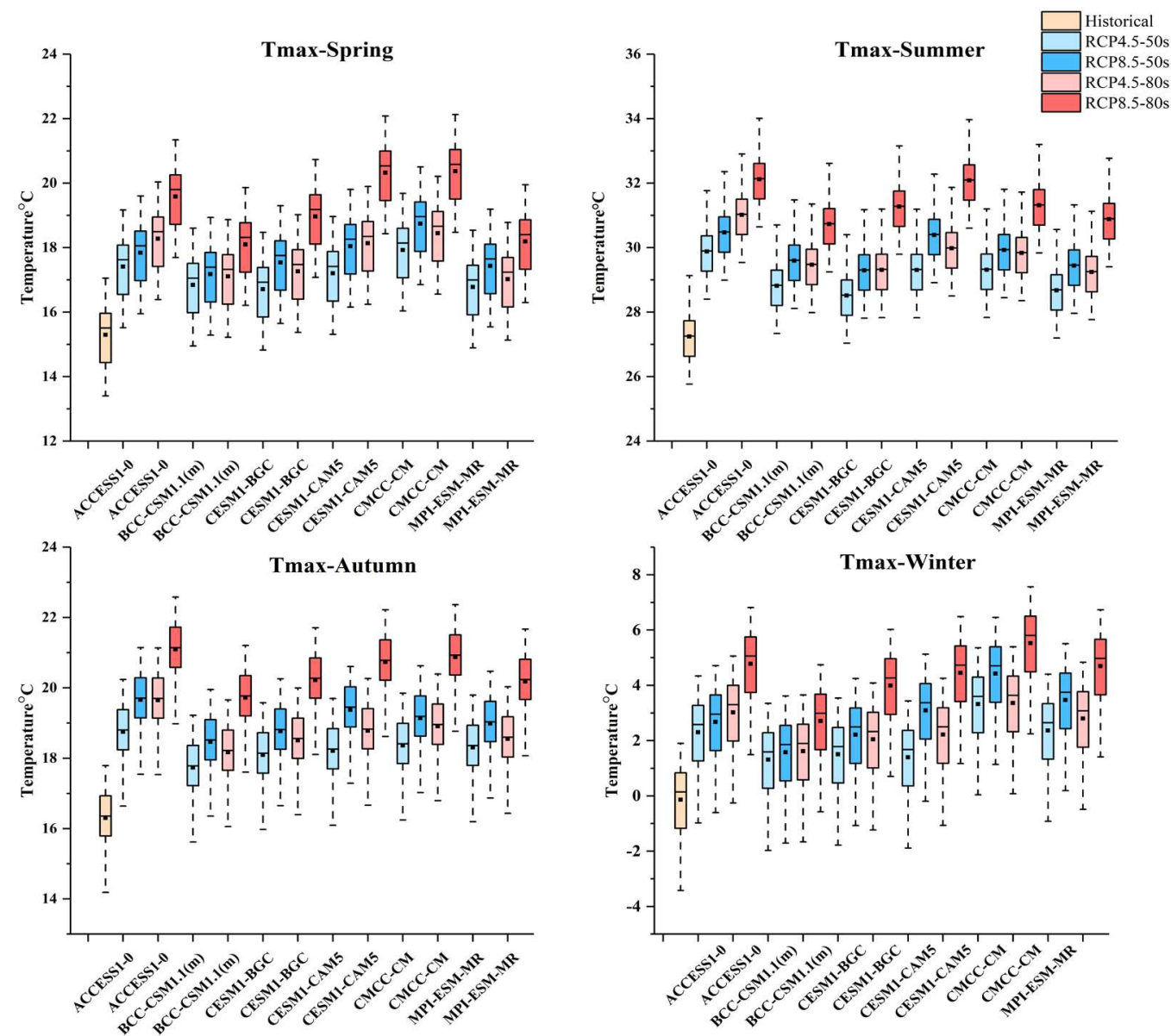

Fig.5a The Tmax in 2050s and 2080s under RCP4.5 and RCP8.5 scenarios based on 6 GCMs compare with reference period (1980-2004). Lower and upper box boundaries indicate the $25^{\text {th }}$ and $75^{\text {th }}$ percentiles, respectively. The black lines and dots inside the box represent the median and mean value, respectively. The lower and upper whiskers indicate the $10^{\text {th }}$ and $90^{\text {th }}$ percentiles, respectively. 

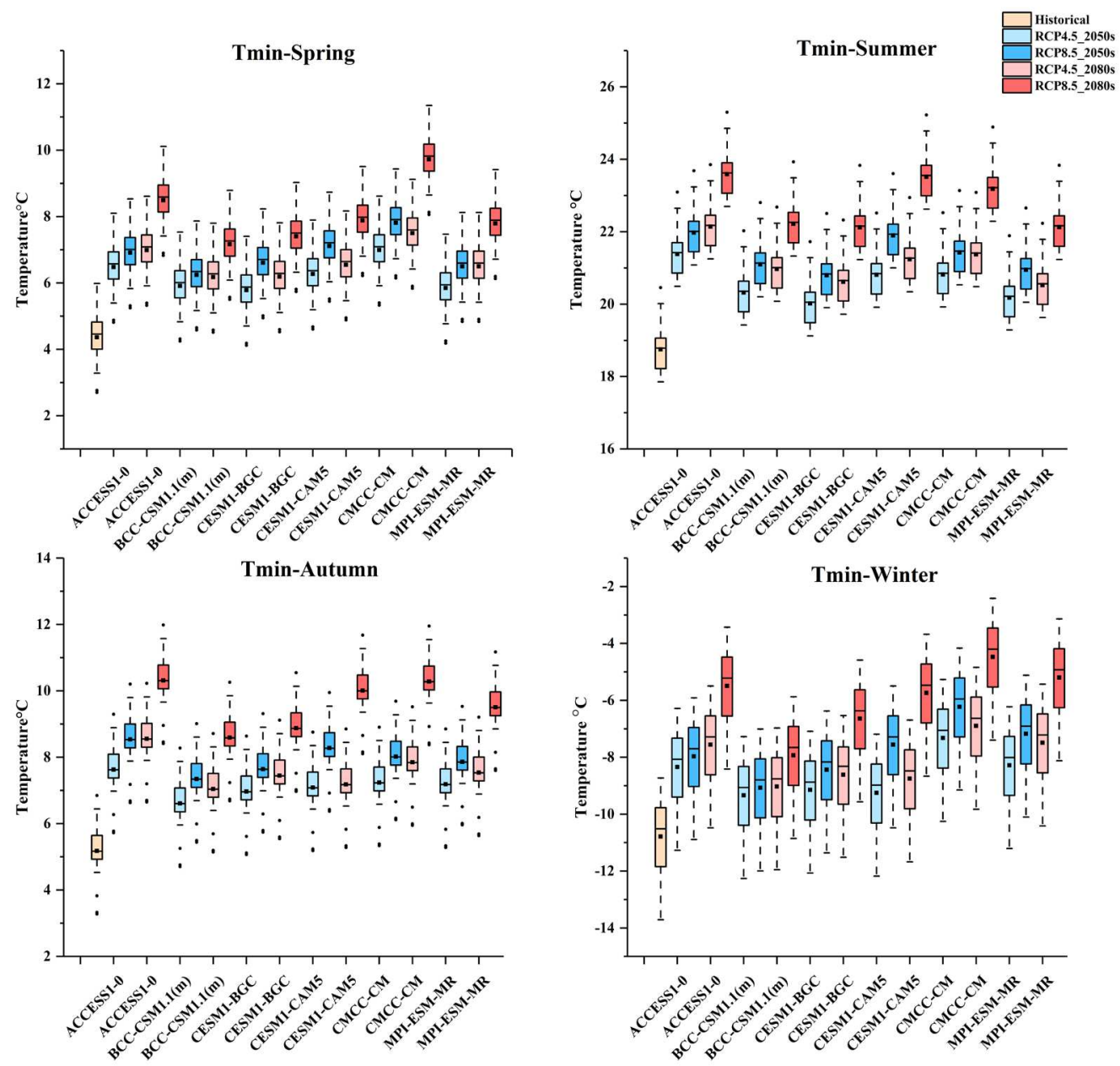

Fig.5b The T-min in 2050s and 2080s under RCP4.5 and RCP8.5 scenarios based on 6 GCMs compare with reference period (1980-2004). Lower and upper box boundaries indicate the $25^{\text {th }}$ and $75^{\text {th }}$ percentiles, respectively. The black lines and dots inside the box represent the median and mean value, respectively. The lower and upper whiskers indicate the $10^{\text {th }}$ and $90^{\text {th }}$ percentiles, respectively.

\subsubsection{Change in ET projections}

The calibrated hydrological model output 100 behavioral simulations for each scenarios member in each month. There are 1200 sets ET projections can be obtained from the hydrological simulation for two future periods, and the future season ET projections comparing with baseline period shows in Fig.6a and Fig.6b. For RCP4.5 and RCP8.5 emission scenarios, the season mean ET projections shows an obvious increased trend in spring, summer and winter. However, the mean ET of autumn demonstrate a relatively smaller increased, some of the models show a decreased trend. In contrast with precipitation and temperature projections, the various of ET projections among each scenarios members are relatively smaller. 

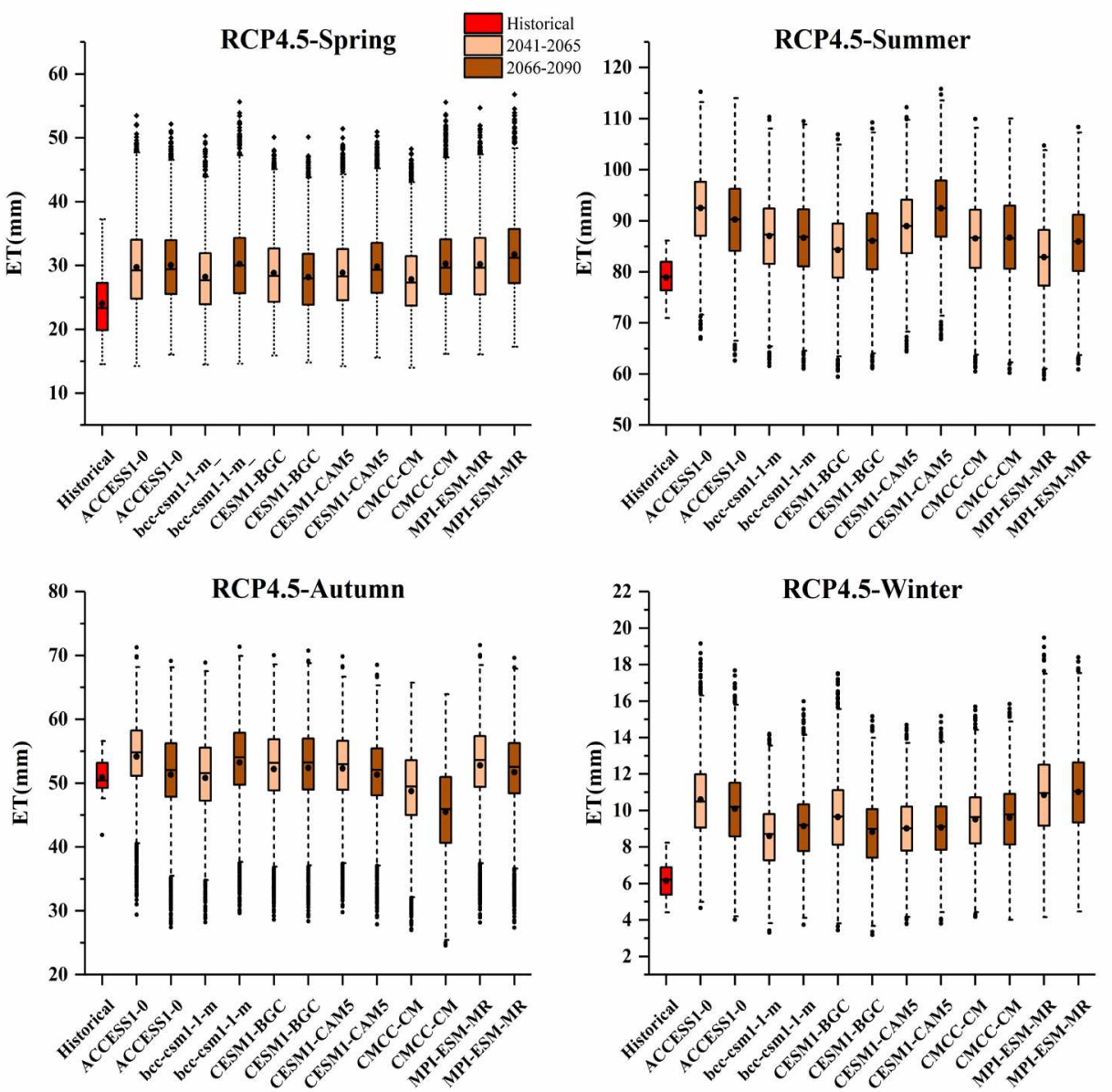

Fig.6a The ET in 2050s and 2080s under RCP4.5 scenarios based on 6 GCMs compare with reference period (1980-2004). Lower and upper box boundaries indicate the $25^{\text {th }}$ and $75^{\text {th }}$ percentiles, respectively. The black lines and dots inside the box represent the median and mean value, respectively. The lower and upper whiskers indicate the $10^{\text {th }}$ and $90^{\text {th }}$ percentiles, respectively. 

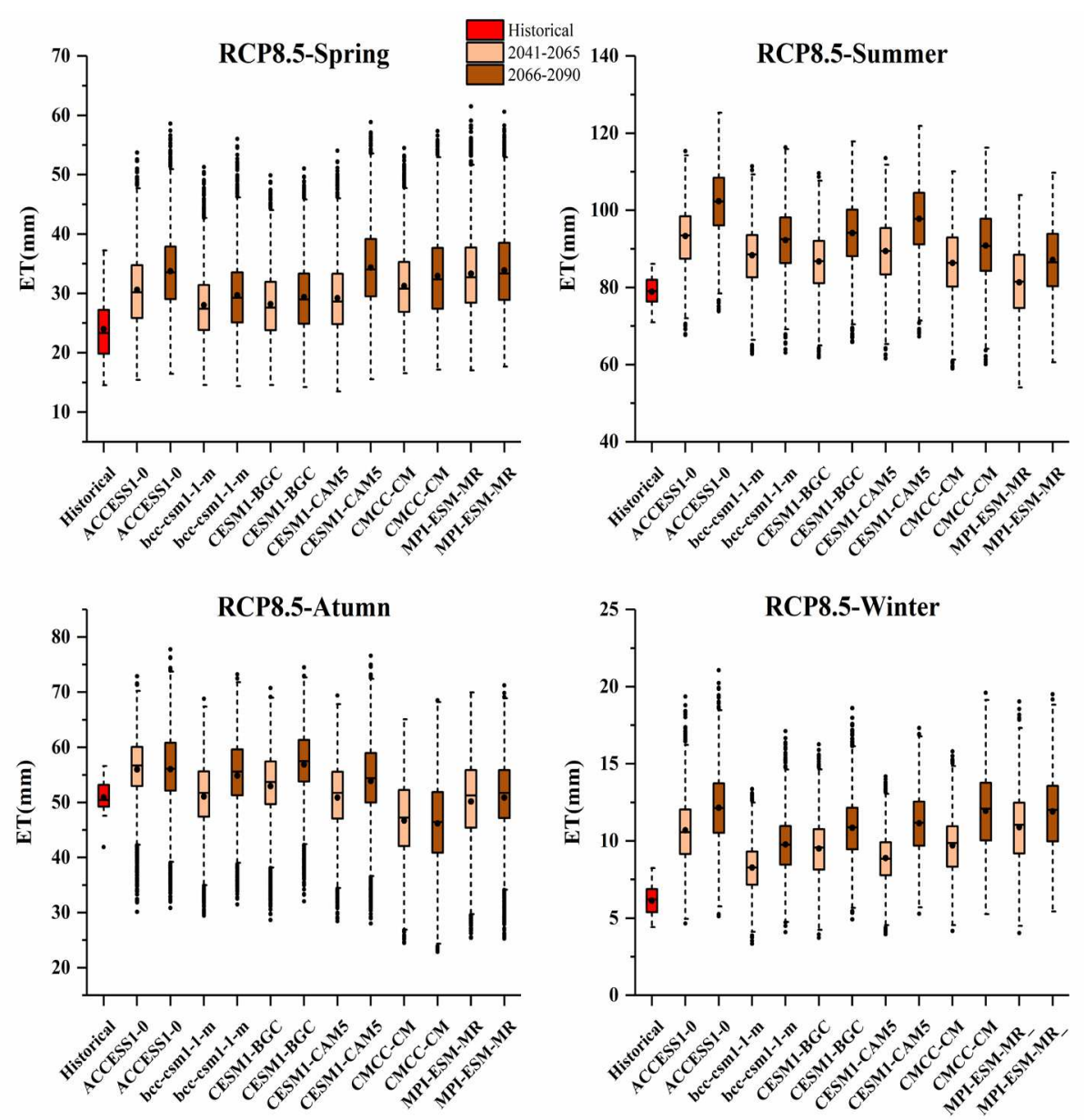

Fig.6b The ET in 2050s and 2080s under RCP8.5 scenarios based on 6 GCMs compare with reference period (1980-2004). Lower and upper box boundaries indicate the $25^{\text {th }}$ and $75^{\text {th }}$ percentiles, respectively. The black lines and dots inside the box represent the median and mean value, respectively. The lower and upper whiskers indicate the $10^{\text {th }}$ and $90^{\text {th }}$ percentiles, respectively.

\subsubsection{Change in runoff projections}

The predicted runoff projections of four seasons in two future periods are compared with the reference period in Fig.7a and Fig.7b, each box and whisker plots for runoff projections are generated from 1200 simulation chains. For 2050s, the runoff projections increase more significant in autumn than the other seasons. In terms of autumn runoff changing, lots of scenarios members show an increased trend in future, ranging 1.37\% 66.01\% under RCP4.5 and $-11.99 \%$ $\sim 97.08 \%$ under RCP8.5. In comparison with autumn runoff, the runoff projections in summer trending a relatively small decreased in future. The range of runoff changing is from $-18.41 \%$ to $47.78 \%$ under RCP4.5 in 2050s, there are four scenarios member demonstrate an decreased trend such as BCC-CSM1.1(m) (-13.70), CESM1-BGC (-18.41), CMCC-CM (-11.81), MPI-ESM-MR (-13.97). The range of runoff changing is from $-52.78 \%$ to $70.41 \%$ under RCP 8.5 in 2050 s, it can 
be found that the diversity of runoff is larger in this scenarios and most of scenarios members shows an decreased trend in future. For 2080s, the obvious changing of runoff is summer and autumn. Most of scenarios members show an increased trend in autumn runoff, the mean changing ratio is $33.89 \%$ under RCP4.5. In contrast with autumn runoff, the runoff changing in summer show a decreased trend, and the mean changing ratio is $-8.56 \%$ under RCP4.5. Similarly, the runoff projections still exist obvious differences among scenarios members. The changing trend of runoff projections demonstrated a consistent increased trend under RCP8.5, the mean changing ratios of spring, summer, autumn and winter is $2.91 \%, 11.95 \%, 85.22 \%$ and $25.68 \%$ respectively.

Furthermore, the diversity of runoff projection still significantly in 2080s under RCP8.5 scenarios.
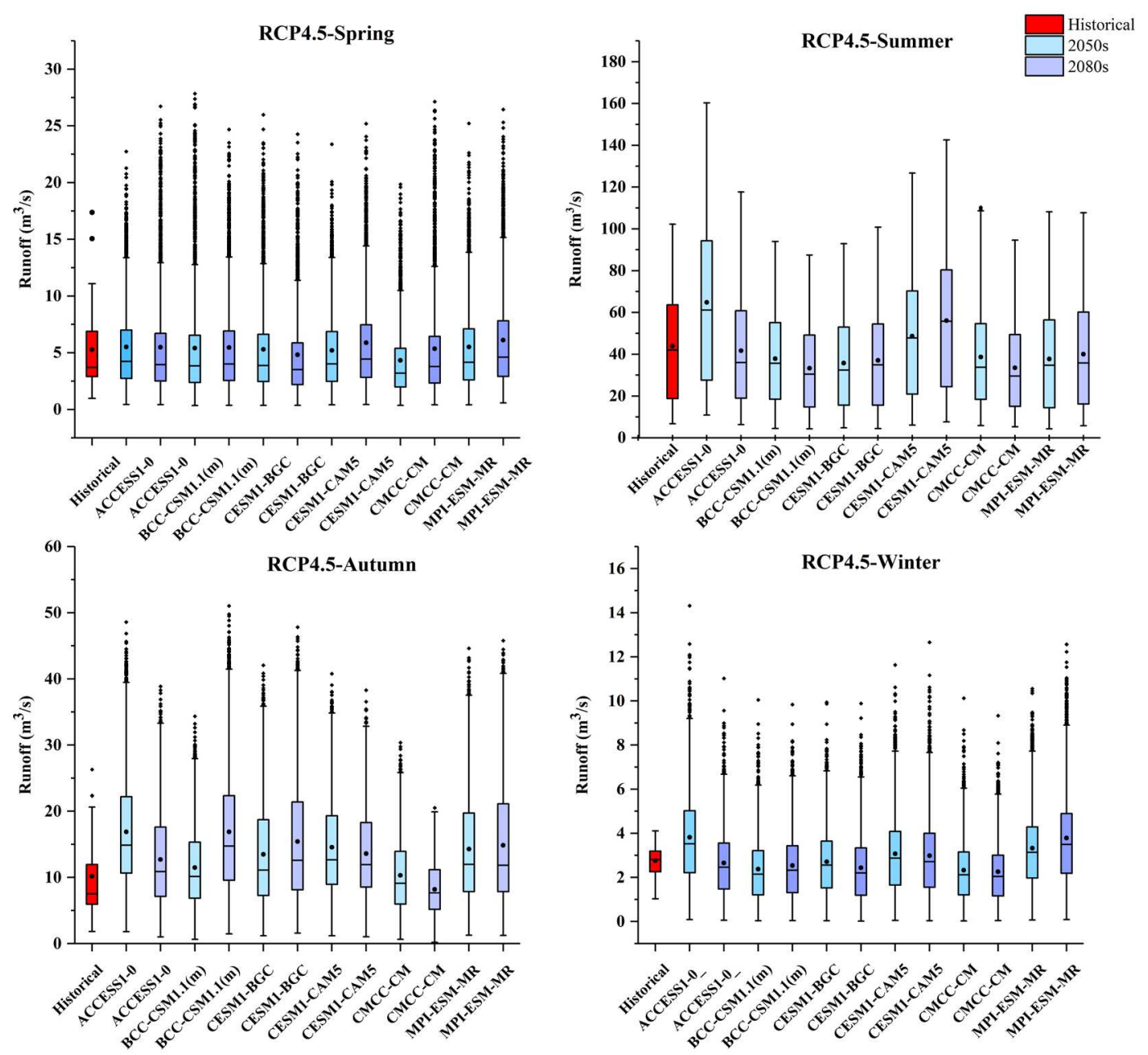

Fig.7a The runoff in 2050s and 2080s under RCP4.5 scenario based on 6 GCMs compare with reference period (1980-2004). Lower and upper box boundaries indicate the $25^{\text {th }}$ and $75^{\text {th }}$ percentiles, respectively. The black lines and dots inside the box represent the median and mean value, respectively. The lower and upper whiskers indicate the $10^{\text {th }}$ and $90^{\text {th }}$ percentiles, respectively. 

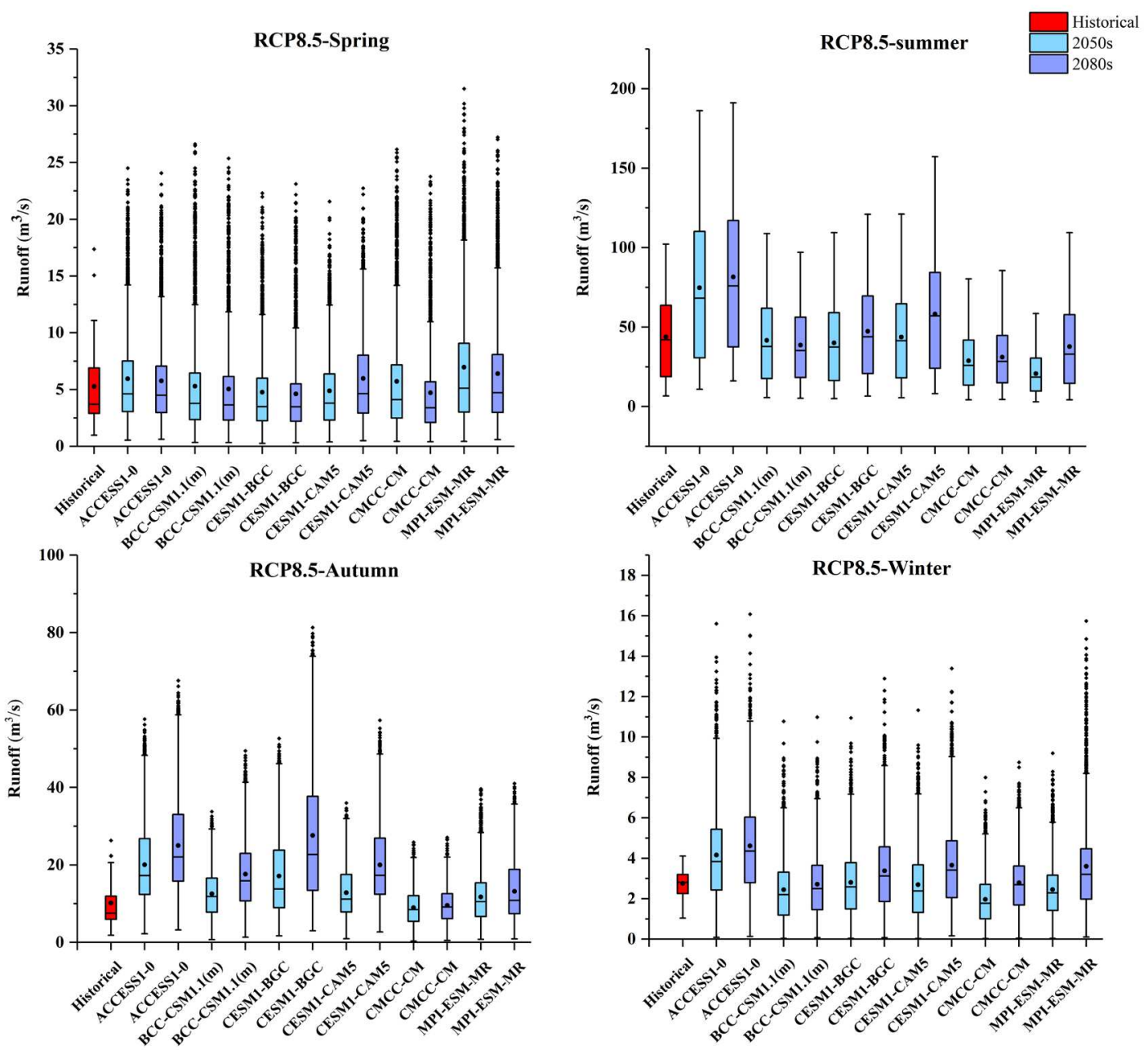

Fig.7b The runoff in 2050s and 2080s under RCP8.5 scenario based on 6 GCMs compare with reference period (1980 2004). Lower and upper box boundaries indicate the $25^{\text {th }}$ and $75^{\text {th }}$ percentiles, respectively. The black lines and dots inside the box represent the median and mean value, respectively. The lower and upper whiskers indicate the $10^{\text {th }}$ and $90^{\text {th }}$ percentiles, respectively.

Furthermore, the box-and-whisker plots show in Fig.7a and Fig.7b, the upper and lower ends represent the highest and lowest runoff, and the change range indicated the uncertainty bound. Compared with the runoff in reference period, the autumn runoff projections reveal a consistent increase in mean and median values under both two emission scenarios and future periods. Most of the summer runoff projections show a decrease trend in future. From the runoff projections changing results, each scenarios member demonstrated a wide uncertainty range inner member, and a obvious diversity among different members. Accordingly, the uncertainty ranges of runoff projections under RCP8.5 projections are larger than RCP4.5 scenarios. Compared with the other seasons, the summer runoff projections showed the largest uncertainty brands under two emission scenarios in future. Observing median values, the summer and autumn projections in 2050s and 
2080s show the non-negligible differences, for example, the median values for summer under RCP4.5 scenario feature a decrease in projections as BCC-CSM1.1(m), CESM1-BGC, CMCC-CM and MPI-ESM-MR, which ranging from $-22.82 \%$ to $-15.04 \%$, in contrast, the median values show an increase from $45.55 \%$ to $13.79 \%$ in projected of ACCESS1 and CESM1-CAM5. In addition, the median values for the spring runoff projections in 2050s under RCP4.5 portray a consistent slight increase from $3.23 \%$ to $12.51 \%$, only CMCC-CM projection show a decrease as $-12 \%$. Overall, the runoff projected by all GCMs showed a large uncertainty in two future periods. Comparing 2050s and 2080s, it can be found that the lower ends become smaller and the upper ends become larger, which indicate that the uncertainty bonds increasing from 2050s to 2080s. In addition, comparing the RCP4.5 and RCP8.5 scenarios, the uncertainty bound of RCP8.5 scenarios are always larger than RCP4.5.

\subsubsection{Impacts of climate factors to runoff change}

After analyzing the changes of climate factors (precipitation, $\mathrm{T}_{\max }, \mathrm{T}_{\min }$ and ET) in future, it can be found that the different climate factors performance different changing trend and uncertainties under climate changing. The different climate factors may effect and produce different uncertainty contribution to runoff changing, hence, it is important to analyze the relationship between climate factors and runoff projections. In order to determine the relationships between them, the multiple linear regression was performed for each model chain using changes of precipitation, $T_{\max }, T_{\min }$ and ET as the independent variables and the runoff as the dependent variables.

The regression coefficients for runoff are shown in Table 3. In general, the increase of precipitation may cause a positive effect on runoff increasing, this trend can be found in all of the models and scenarios and coefficients at the 0.001 significant level. In contrast, the increase of ET projections was negatively related to runoff, and there are seven projections at the 0.001 significant level. In addition, the increase $\mathrm{T}_{\max }$ and $\mathrm{T}_{\min }$ may contribute the increase trend of runoff, however, the coefficients did not pass the significant test even at 0.05 level. In most scenarios members, the precipitation and ET had a significant influence in runoff projection and temperature had a slight influence, hence, the internal variability of climate factor need be investigate specifically. 
Table 3 The multiple liner regression coefficients for runoff $\left(\mathrm{R} \mathrm{mm}\right.$ year $\left.{ }^{-1}\right)$ with maximum temperature $\left(\mathrm{T}_{\max }{ }^{\circ} \mathrm{C}\right)$,

450 minimum temperature $\left(\mathrm{T}_{\min }{ }^{\circ} \mathrm{C}\right)$, precipitation $\left(\mathrm{P} \mathrm{mm} \mathrm{year}{ }^{-1}\right)$ and $\mathrm{ET}\left(\mathrm{mm} \mathrm{year}^{-1}\right)$ in a multiple linear regression

$451 \operatorname{model}\left(\mathrm{R}=\mathrm{a}_{1} \mathrm{~T}_{\max }+\mathrm{b}_{1} \mathrm{~T}_{\min }+\mathrm{c}_{1} \mathrm{P}+\mathrm{d}_{1} \mathrm{ET}+\mathrm{e}_{1}\right) . \mathrm{p}$ is the significant level: ***: $\mathrm{p}<0.001, * *: \mathrm{p}<0.01, * \mathrm{p}<0.05$.

\begin{tabular}{lcccccc}
\hline \multicolumn{1}{c}{ Models } & $\mathrm{a}_{1}$ & \multicolumn{1}{c}{$\mathrm{b}_{1}$} & \multicolumn{1}{c}{$\mathrm{c}_{1}$} & \multicolumn{1}{c}{$\mathrm{d}_{1}$} & $\mathrm{e}_{1}$ & $\mathrm{R}^{2}$ \\
\hline ACCESS1-0_RCP45 & 22.75 & -21.40 & $0.92^{* * *}$ & $-0.97 * * *$ & $-197.62^{* *}$ & 0.96 \\
ACCESS1-0_RCP85 & 61.05 & 23.89 & $0.97 * * *$ & -0.86 & -1284.58 & 0.75 \\
BCC-CSM1.1(m)_RCP45 & 20.96 & -15.30 & $0.85^{* * *}$ & $-0.81^{* * *}$ & -237.05 & 0.92 \\
BCC-CSM1.1(m)_RCP85 & 17.26 & -13.92 & $0.84 * * *$ & $-0.76^{* *}$ & -205.54 & 0.93 \\
CESM1(BGC)_RCP45 & 28.98 & -25.77 & $0.86 * * *$ & $0.21 * * *$ & -209.88 & 0.93 \\
CESM1(BGC)_RCP85 & 81.42 & -38.46 & $0.99^{* * *}$ & -0.5 & $-1370.22 * * *$ & 0.86 \\
CESM1(CAM5)_RCP45 & 18.15 & -17.34 & $0.90^{* * *}$ & -0.93 & -153.06 & 0.96 \\
CESM1(CAM5)_RCP85 & 22.13 & -20.34 & $0.87 * * *$ & $-0.77 * * *$ & -265.73 & 0.96 \\
CMCC-CM_RCP45 & 5.92 & 18.26 & $0.62 * * *$ & -0.53 & -248.50 & 0.75 \\
CMCC-CM_RCP85 & 15.40 & -14.67 & $0.68^{* * *}$ & $-0.45 *$ & -235.24 & 0.87 \\
MPI-ESM-MR_RCP45 & 29.52 & -24.95 & $0.88^{* * *}$ & $-1.02^{* * *}$ & -224.86 & 0.94 \\
MPI-ESM-MR_RCP85 & 24.93 & -15.04 & $0.77 * * *$ & $-0.65^{* *}$ & -348.45 & 0.90 \\
\hline
\end{tabular}

452

453

\subsection{Evaluation and investigation the source of uncertainty}

\subsubsection{Estimating the role of internal variability}

The role of internal variability in hydrological climate-impact projections is partitioned and quantified in this section. In order to investigate the internal variability of the precipitation trends, six GCMs are forced by the same emission scenarios, and then the CIV values of the hydrological climate-impact projections under two emission scenarios were shown in Fig.8.

The CIV values of precipitation are higher in rainy season (June to September) and the lowest values appeared in winter. It is demonstrated that the internal variability play an important role on the uncertainty of flood season precipitation. Similarly, the CIV values of ET are larger in May to September than the other months. In contrast, the CIV values of $T_{\max }$ and $T_{\min }$ are relatively smaller in rainy season. Moreover, the CIV values of runoff demonstrate that the internal variability is higher in rainy season than the other seasons, these trend is similarly with the CIV of precipitation and ET projections. According to the multiple linear regression of the climate factors, the precipitation and ET have significant influence on runoff, it can imply that the internal variability of precipitation and ET may influence the internal variability of runoff.

From the CIV values of runoff projections under RCP4.5 and RCP8.5 emission scenarios, it can be found that the CIV values of rainy season are larger than the other seasons, and the maximum CIV value of the runoff projections appeared in August. Compared the CIV values of precipitation, 
temperature, ET and runoff projections, the internal variability of precipitation and runoff showed obvious increased in rainy season. On consideration of the internal variability may combine with the model and scenarios uncertainties and then influencing the runoff, hence, the contribution of internal variability need be special investigated.
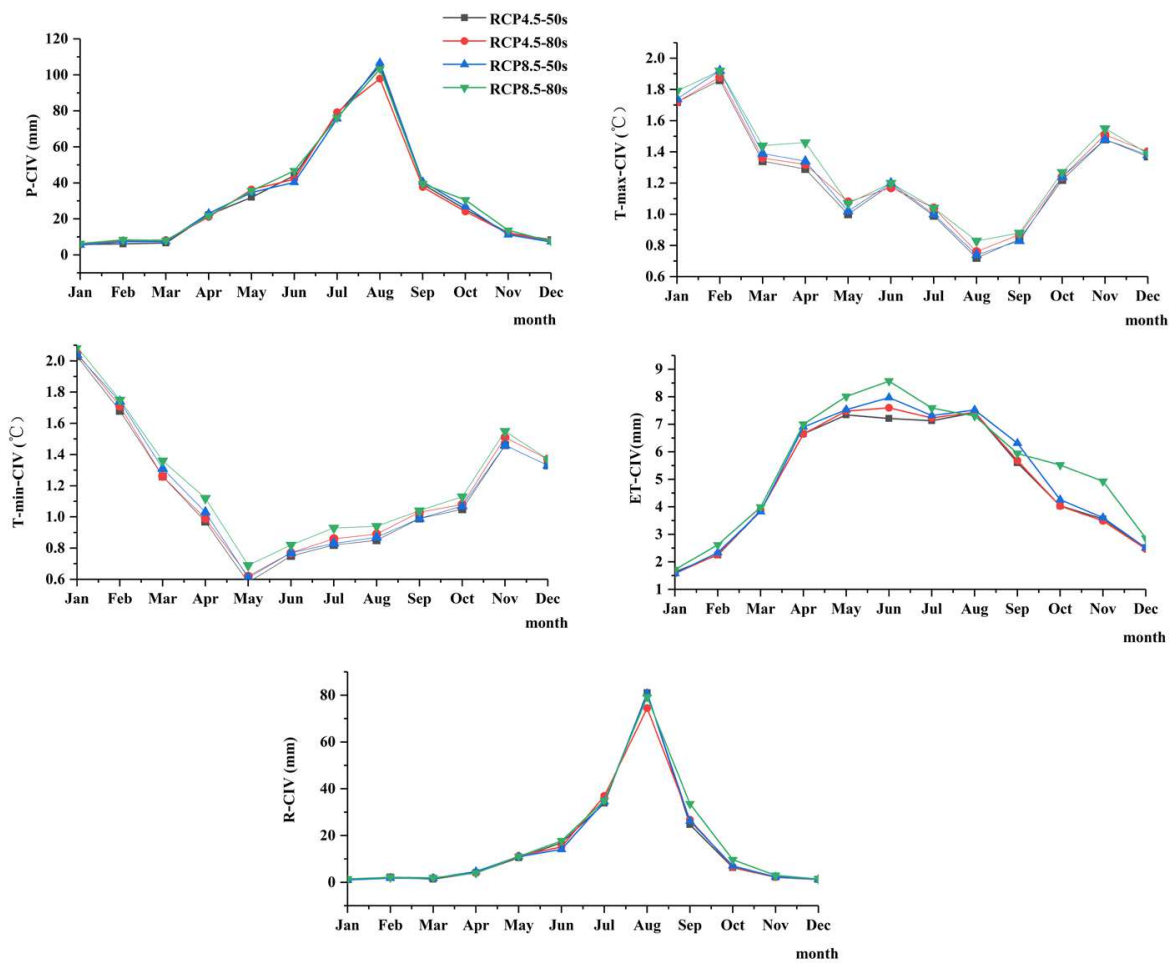

Fig.8. The CIV values of hydrological climate-impact projections

The SNR can give some useful information for investigating the role of internal variability. The SNR values of precipitation, temperature, ET and runoff are showed in Fig.9. This metrics convey information about the magnitudes of the forced and internally generated components of hydrological climate-impact projections under future climate change. The SNR of ET and temperature show an obvious changing in spring, summer and autumn.The SNR values of $\mathrm{T}_{\max }$ and $\mathrm{T}_{\min }$ demonstrated a relatively higher values in June to October, it worth noting that the external forcing is the mainly impact factors in these month. Similarly, the SNR of ET is higher in June to October than the other month, hence, the internal variability of temperature and ET is weaker in these season. In contrast, the SNR of precipitation and runoff are relatively stable among four seasons. An important result is that the internal variability contributed a considerable higher component in precipitation and runoff than temperature and ET. On the base of the estimating of internal variability, it can be observed that the SNR values of the precipitation and 
runoff mostly around 1 in each month. It means the significance of internal variability is approximate with external forcing. However, the SNR values can't able to quantify the internal variability. It is important to partition and confirm the specific internal variability and other uncertainty source contribution inner year.
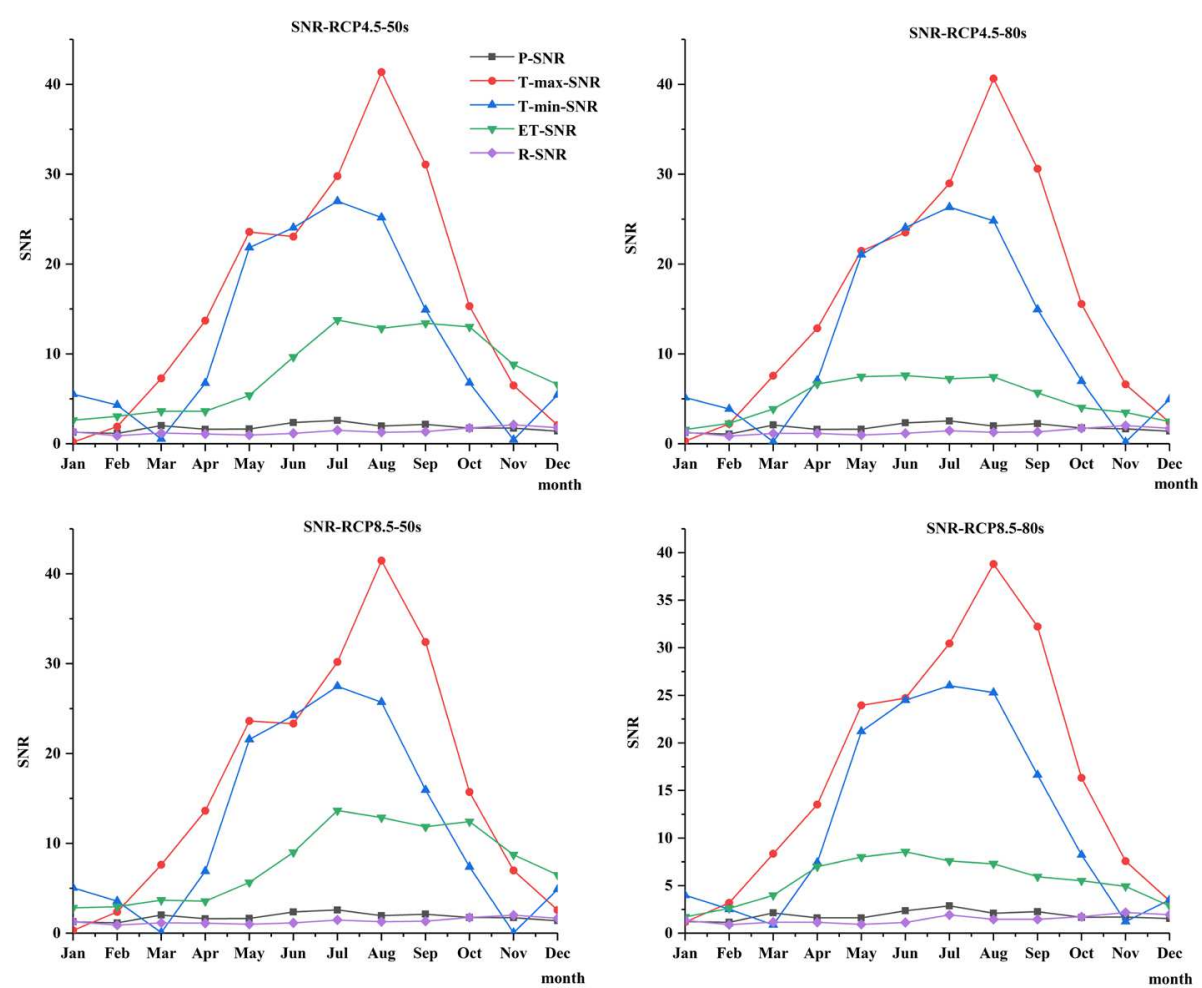

Fig.9 The SNR values of hydrological climate-impact projections

\subsubsection{Contribution analysis of uncertainty sources}

As mentioned previously, the uncertainty sources of hydrological climate-impact projections involve model uncertainty, scenarios uncertainty and internal variability. The ANOVA method is 2080s. 

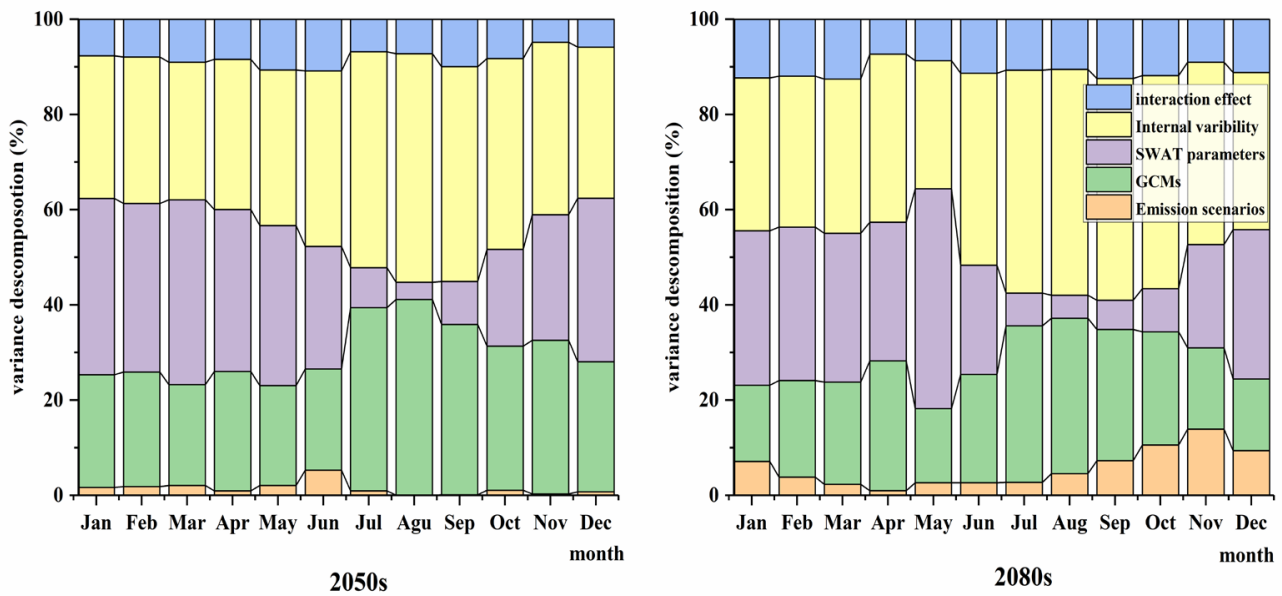

500

501

502

503

504

Fig.10 The contribution of uncertainty sources to the runoff in 2050s and 2080s period.

The contribution of uncertainty sources showed in Fig.10. It is noteworthy that the effect of internal variability is significant among all of the month in 2050s and 2080s period. The contribution of internal variability is almost equal with the sum of the uncertainty of GCMs and emission scenarios. It contributes $29 \% \sim 48 \%$ and $31.4 \% \sim 47.4 \%$ of the total variance in 2050 s and 2080s, respectively. Moreover, the biggest contribution embodies in September in two future periods. The other two mainly uncertainty contributors are GCMs and SWAT model parameter sets. The uncertainty of GCMs account for $21 \% \sim 41 \%$ and $15 \% \sim 33 \%$ in 2050 s and 2080 s, and the biggest value is in September (2050s) and August (2080s) respectively. For the SWAT model parameter sets, the contribution accounts for $4 \% \sim 39 \%$ and $4.8 \% \sim 32.4 \%$ in 2050 s and 2080 s, respectively. Compared with the previous two uncertainty sources, the SWAT model parameters main effect the Spring (March to May) and Winter (December to February) runoff projections. The interaction term contribution to the runoff projection explaining approximately $8 \% \sim 11 \%$ and $7 \% \sim 12 \%$ throughout the 2050 s and 2080 s periods, respectively. The contribution of emission scenarios is relatively small, which bellows $5 \%$ and $10.5 \%$ in 2050 s and 2080 s, respectively.

Overall, the results of uncertainty decomposition in Fig. 10 indicate that internal variability and GCMs are dominant uncertainty contributor of runoff in June to October. In addition, SWAT model parameters are the mainly uncertainty contributor in spring and winter. In summary, the internal variability and GCMs provide mainly uncertainty contribution in summer and early autumn, and the mainly uncertainty contributor of runoff in spring and winter are internal variability and SWAT model parameters. 


\section{Discussion}

\subsection{Hydrological cliamte-impact projections changing}

This study estimated hydrological climate-impact projections changes under climate change impacts in a respective watershed in Northeastern China. Compared with the reference period, the temperature and precipitation projections performance an increased trend in two future periods, and this increased trend is more significant under RCP8.5 emission scenarios and later future period as 2080s. This finding is consistence with some previous publications, Wang et al. (2020) found that the response of hydrological extreme events to climate changing shows much higher in 2070-2099 under RCP8.5 scenarios. In addition, the ET projections shows obvious increase trend in summer and winter, and a relatively small increase trend in autumn. It can be found that the runoff projections show an increased trend in autumn and a slight decreased trend in summer. With the combined influence of increasing precipitation, temperature and ET in summer, there is a high possibility that runoff would decrease in summer. In contrast, a relative sightly increase of ET in autumn may due to run off increase. Since precipitation, temperature and ET are important input to hydrological model, thus the uncertainties of these projections may also influence runoff projections. Moreover, through the multiple linear regression analysis, the precipitation and $\mathrm{T}_{\max }$ had a significant positive effect on runoff, ET and $\mathrm{T}_{\min }$ shows a relatively small negative effect on runoff. Hence, the increase precipitation and relatively small increase ET may due to a relatively obvious increased in autumn.

This manuscript also found the predication of both hydrological climate-impact projections showed wider range under RCP8.5 than RCP4.5, especially in 2080s. Moreover, the projected of runoff in future also demonstrated an obvious diversity in future, especially in Summer and Autumn. To deal with the uncertainty in future runoff, the details of sources of uncertainties need to be investigated and quantified, so that a relatively reliable hydrological projections are produced.

\subsection{The role of internal variability}

Since the internal variability plays an important role in the uncertainties of the hydrologial climate-impact projections, thus the CIV of future projections has been investigated under RCP4.5 and RCP8.5. The findings indicated that the internal variability of precipitation, ET and runoff are larger in June and September than the other month. In order to investigate the magnitudes of the 
external forcing and internal variability, the SNR of future projections has been investigated under RCP4.5 and RCP8.5. The SNR values of precipitation and runoff are stable, the values are all around 1 among 12 months, which means that the internal variability and external forcing performance an equality effect. However, it is difficult to determine which is the important influence source of hydrologial climate-impact projections only by the SNR values. Considering the June to September contains the entirely flood season in research watershed, the annual internal variability and external forcing uncertainty contribution of runoff projections need be investigated particularly.

\subsection{Estimating the source of uncertainties}

The ANOVA framework was constructed to quantify the uncertainty sources contribute to the overall uncertainty, furthermore, in considering the substantial effects of internal variability on the uncertainty of runoff projections, the uncertainty contribution of internal variability has been considered to ensure the comprehensive of uncertainty assessment.

Quantifying the source of uncertainties contribution to future runoff projections can provide insights into finding the mainly effect factors of runoff variety under climate changing. On the base of the SNR values of different projections, the internal variability and external forcing of precipitation and runoff shown equally significance, which can be embodied in uncertainty estimating. In rainy season (June to September), the internal variability and GCMs are the mainly uncertainty contributors in runoff projections. In contrast, the internal variability and SWAT model parameter sets provided obvious uncertainty to runoff in January to May and October to December.

These findings indicate that the internal variability is the important uncertainty sources among the different sources chosen by this study, which agree with the findings of some previous publications (Lafaysse et al. 2014; Hingray et al. 2019). Meanwhile, the runoff projections are significantly impact by the choices of GCMs, this point also has been found in many studies (Kujawa et al. 2020), for instance, Zhang et al. (2021) found the disparity between different GCMs may mainly impacted the climate change researches, and the increased sample sized of GCMs may conduct a complete uncertainty assessment. As an important tool for runoff simulation and prediction, the hydrological model is a non-negligible uncertainty contributor of overall uncertainty, among the uncertainty derive form the hydrological model, the model parameters 
obtained more attention (Keller et al. 2019; Vaghefi et al. 2019; Nerantzaki et al. 2020). Moreover, the contribution of and interaction effect are relatively small compared with the other uncertainty sources, these findings consist with some previous researches (Bosshard et al. 2013; Qi et al. 2016; Vaghef et al. 2019).

The quantifying of internal viability has been demonstrated in several previous studies (Lafaysse et al. 2014; Evin et al. 2019; Hingray et al. 2019), however, most of the studies focused on decomposition the internal uncertainty of climate system through hydrological simulation process (Doi and Kim. 2020; Yu et al. 2020; Maher et al. 2020; Hawkins and Sutton. 2011). Moreover, this study indicates that the internal variability, GCMs model, emission scenarios, hydrological model parameters and interaction effects need be quantified entirely. Because of the annual distribution contribution of different sources are the important information of uncertainty analysis. The contribution of uncertainty sources in each month can be found in the uncertainty quantified results straightforward.

On consideration of the internal variability may propagate in the hydrological simulation process and then effected the runoff uncertainty. Quantifying the internal variability of precipitation, temperature and ET can provide some useful information to runoff uncertainty analysis. For rainy season, the internal variability and GCMs are the dominant uncertainty in runoff. On the base of multiple linear regression, the precipitation and ET has significantly influence on runoff, and their uncertainty can also influence on runoff uncertainty. From the CIV and SNR values of climate projections, it can be found that the internal variability of precipitation and ET are large in rainy season. Hence, the internal variability of precipitation and ET may affect runoff to some extent. Above all, the internal variability obvious role of the in shaping overall uncertainty, and some of the uncertainty source of runoff projections can be trace bake to precipitation and ET etc.

\section{Conclusion}

The details of sources of uncertainty in hydrological climate-impact projections has been investigated and quantified in this manuscript. The uncertainty quantifying and estimating are essential for the runoff prediction. In addition, identifying the fundamental uncertainty source is meaningful to reduce existing uncertainties in future. The main conclusions of this study can be summarized as flowing: 
612 (1) Based this study analysis of future climate conditions for the Biliu River basin, it can be found

613 that the precipitation and temperature shown an increasing trend in future, especially in RCP8.5

614 and later future period. In addition, the climate factors may produce different influence and 615 uncertainty contribution to runoff changing. For instance, the precipitation has a significant 616 positive effect on runoff and ET shows a relatively small negative effect. Hence, the changing of 617 precipitation and ET may due to corresponding changing in runoff. Furthermore, the wide 618 uncertainty ranges can be found in each projections, the sources of uncertainty may obvious 619 influenced the reliable of hydrological process simulation in future.

620 (2) By elucidating the impact of climate internal variability of runoff projections, this study 621 analysis the role of internal variability of hydrological climate-impact projections and find out the 622 important influence factor of uncertainty of runoff projections. In term of precipitation and ET, the 623 internal variability is larger in June to September, and the SNR values also shows the internal 624 variability and external forcing are both important influence factors to runoff. Combining with the internal variability and GCMs are the dominate uncertainty contributors in June to September. It is worth noting that the internal variability can propagate in the hydrological simulation process, and the internal variability of runoff projections is remarkable in flood season of study watershed in future. As the rain season in the study basin, some water resources adaptation measures need be planned to alleviate the climate change influence, especially in high emission scenarios (RCP8.5) and far future (2080s).

631 (3) The uncertainty contribution of internal variability with GCMs and SWAT model parameters 632 are temporal variability. The internal variability and GCMs are the mainly uncertainty contributors 633 OF runoff projections, IN rainy season (June to September). In contrast, the internal variability and 634 SWAT model parameter sets provided obvious uncertainty to runoff in January to May and 635 October to December. The findings of this study indicate that the role of internal variability of 636 hydrological climate-impact projections is noticeable in future, these kinds of effect may 637 extremely influence the stakeholders and local water resources government to provide correct 638 hydrological regulation and flood control measures. 
Funding Statement

This study was sponsored by the Open Research Fund of State Key Laboratory of Simulation and Regulation of Water Cycle in River Basin, China Institute of Water Resources and Hydropower Research, Grant NO. IWHR-SKL-202103. (Wenjun Cai)

\section{Conflicts of interest/Competing interests}

The authors declare that they have no known competing financial interests or personal relationships that could have appeared to influence the work reported in this paper.

\section{Author's Contribution}

Conceptualization, Xuehua Zhao and Jia Liu; Methodology, Wenjun Cai and Jia Liu; Formal Analysis, Wenjun Cai and Jia Liu; Writing Original Draft Preparation Wenjun Cai and Xueping Zhu; Writing — Review \& Editing, Wenjun Cai and Jia Liu; Funding Acquisition, Wenjun Cai.

Availability of data and material

The climate data in 1901-2099 for RCP4.5 and RCP8.5 were downloaded from the National Climate Center (http://ncc.cma.gov.cn). The long-term experiment data of 1850-2100 for the chosen six climate models in CMIP5 were downloaded from the Program for Climate Model Diagnosis and Itercomparison (PCMDI, http://pcmdi3.llnl.gov/esgcet/). Yearly and monthly precipitation and runoff data in 1958-2011 were obtained from the Biliu River Reservoir administration. Month meteorological data were obtained from the China Meteorological Data Sharing Service System (http://cdc.cma.gov.cn/inex.jsp). The Digital Elevation Model (DEM) data $(90 \times 90 \mathrm{~m})$ were obtained from the CGIAR Consortium for Spatial Information (CGIAR-CSI) (http://srtm.csi.cgiar.org). Soil type and land use maps were obtained from the Data Center for Resources and Environmental Sciences, Chinese Academy of Sciences (http://www.resdc.cn/fist.asp).

Code availability

The calculate code of climate internal variability and ANOVA are according to the corresponding formulas, which has already described in this manuscript.

\section{Ethics approval}

ALL that data and analysis in this manuscript are ethics approval.

\section{Consent to participate}

This manuscript consent to participate.

Consent for publication

This manuscript consent to publication.

\section{Acknowledgements}

This study was sponsored by the Natural Science Foundation of Shanxi Province, China. Grant No.201901D111060 and the Open Research Fund of State Key Laboratory of Simulation and 
Regulation of Water Cycle in River Basin, China Institute of Water Resources and Hydropower Research, Grant NO. IWHR-SKL-202103. We would also like to acknowledge the World Climate Research Programme's Working Group on Coupled Modeling, which is responsible for CMIP.

\section{References:}

Anjum M N, WahabA, Huggel C, Qamar M U, Hussain E, Ahmad S, Waheed A (2019) Simulation of the projected climate change impacts on the river flow regimes under CMIP5 RCP scenarios in the westerlies dominated belt, northern Pakistan. Atmospheric Research 227: 233-248. https://doi.org/10.1016/j.atmosres.2019.05.017

Abbaspour K C, Yang, Maximov I, Siber R, Bogner K, Mieleitner J, Zobrist J, Srinivasan R (2007) Modelling hydrology and water quality in the pre-alpine/alpine Thur watershed using SWAT, Journal of Hydrology 333:413-430. https://doi:10.1016/j.jhydrol.2006.09.014

Abbaspour K C, Johnson C A, van Genuchten M T (2004) Estimating Uncertain Flow and Transport Parameters Using a Sequential Uncertainty Fitting Procedure. Vadose Zone Journal 3:1340-1352. https://doi:10.2113/3.4.1340 Aryal A, Shrestha S, Babel M S (2017) Quantifying the sources of uncertainty in an ensemble of hydrological climate-impact projections. Theoretical and Applied Climatology 135: 193-209. https://doi.org/10.1007/s00704-017-2359-3

Byun, K, Chiu C M, Hamlet A F (2019) Effects of 21st century climate change on seasonal flow regimes and hydrologic extremes over the Midwest and Great Lakes region of the US. Science of the Total Environment 650: 1261-1277. https://doi.org/10.1016/j.scitotenv.2018.09.063

Bosshard T, Carambia M, Goergen K, Kotlarski S, Krahe P, Zappa M, Schar C (2013) Quantifying uncertainty sources in an ensemble of hydrological climate-impact projections. Water Resources Research 49:1523-1536. https://doi:10.1029/2011WR011533

Belcher S E, Hacker J N, Powell D S (2005) Constructing design weather data for future climates. Building Services Engineering Research and Technology 26: 49-61. https://doi.org/10.1191/0143624405bt112oa

Beven K, Binley A (1992) The future of distributed models: model calibration and uncertainty prediction. Hydrological Processes 6(3): 279-298. http://doi/abs/10.1002/hyp.3360060305

Chen J, ST-Denis B G, Brissette F P, Lucas-Picher P (2016) Using Natural Variability as a Baseline to Evaluate the Performance of Bias Correction Methods in Hydrological Climate Change Impact Studies. American Meteorological Society 17: 2155-2173. https://doi: 10.1175/JHM-D-15-0099.1

Chawla I, Mujumdar P P (2018) Partitioning uncertainty in streamflow projections under nonstationary model conditions. Advances in Water Resources 112: 266-282. https://doi.org/10.1016/j.advwatres.2017.10.013

Chen S T, Yu P S, Tang Y H (2010) Statistical downscaling of daily precipitation using support vector machines and multivariate analysis. Journal of Hydrology 385(1-4): 13-22. https: doi:10.1016/j. jhydrol.2010.01.021

Champagne O, Arain M A, Leduc M, Coulibaly P, McKenzie S (2020) Future shift in winter sreamflow modulated by the internal variability of climate in southern Ontario. Hydrology and Earth System Sciences 24: 3077-3096.

Deser C, Phillips A, Bourdette V, Teng H M (2012) Uncertainty in climate change projections: the role of internal variability, Climate Dynamic 38:527-546. http://doi 1007/s00382-010-0977-x

Deser C, Phillips A, Alexander M A, Smoliak B V (2014) Projecting north American climate over next 50 years: uncertainty duo to internal variability. http://doi 10.1175/JCLI-D-13-00451.1

Doi Van, Kim M. J (2020) Projections on climate internal variability and climatological mean at fine scales over South Korea. Stochastic Environmental Research and Risk Assessment 34(7): p. 1037-1058. https://doi.org/10.1007/s00477-020-01807-y 
Evin G, Hingra B, Blanche, J Eckert N, Morin, Verfaillie (2019) Partitioning Uncertainty Components of an Incomplete Ensemble of Climate Projections Using Data Augmentation. Jounal of Climate 32:2423-2440. https://doi. 10.1175/JCLI-D-18-0606.1

Ficklin D L, Letsinger S L, Stewart I T, Maurer E P (2016) Assessing differences in snowmelt-dependent hydrologic projections using CMIP3 and CMIP5 climate forcing data for the western United States. Hydrology Research 47: 483-500. https://doi: 10.2166/nh.2015.101.

Frankcombe L M, England M H (2015) Separating Internal Variability from the Externally Forced Climate Response. Journal of Climate. 28: 8184-8202. https://doi: 10.1175/JCLI-D-15-0069.1

Gupta A, Govindaraju R S (2019) Propagation of structural uncertainty in watershed hydrologic models. Journal of Hydrology 575: 66-81. https://doi.org/10.1016/j.jhydrol.2019.05.026

Galavi H, Mirzaei M (2020) Analyzing Uncertainty Drivers of Climate Change Impact Studies in Tropical and Arid Climates. Water Resources Management 34: 2097-2109. https://doi.org/10.1007/s11269-020-02553-0

Hawkins E, Sutton R (2009) The potential to narrow uncertainty in regional climate predictions. American Meteorological Society 90(8):1095-1108. https://doi.10.1175/2009bams2607.1

Hawkins E, Sutton R (2011) The potential to narrow uncertainty in projections of regional precipitation change. Climate Dynamic 37: 407-418. http://doi 10.1007/s00382-010-0810-6

Hingray B, Blanchet J, Evin G, Vidal J P (2019) Uncertainty component estimates in transient climate projections: Precision of estimators in a single time or time series approach. Climate Dynamic 4635-1. https ://doi.org/10.1007/s0038 2-019-04635-1

Kujawa H, Kalcic M, Martin J, Aloysius N, Apostel A, Kast J, Murumkar A, Evenson G, Becker R, Keller L, Zischg A P, Mosimann M, Rössler O, Weingartner R, Martius O (2019) Large ensemble flood loss modelling and uncertainty assessment for future climate conditions for a Swiss pre-alpine catchment. Science of The Total Environment 693:133400. https://doi.org/10.1016/j.scitotenv.2019.07.206

Keller, L., Zischg, A. P., Mosimann, M., Rössler, O., Weingartner, R., \& Martius, O. (2019). Large ensemble flood loss modelling and uncertainty assessment for future climate conditions for a Swiss pre-alpine catchment. Science of The Total Environment.693: 133400 https://doi:10.1016/j.scitotenv.2019.07.206.

Kim J, Tanveer M E, Bae D H (2018) Quantifying climate internal variability using an hourly ensemble generator over South Korea. Stochastic Environmental Research and Risk Assessment 32:3037-3051. https://doi.org/10.1007/s00477-018-1607-0

Li L, Diallo I, Xu C Y, Stordal F (2015) Hydrological projections under climate change in the near future byRegCM4 in Southern Africa using a large-scale hydrological model. Journal of Hydrology 528:1-16. http://dx.doi.org/10.1016/j.jhydrol.2015.05.028

Liu Y, Zhang J Y, Wang G Q, Liu J F, He R M, Wang H J, Liu C S, Jin J L (2012) Assessing the effect of climate natural variability in water resources evaluation impacted by climate change. Hydrological Processes 27(7):1061-1071. https://doi: 10.1002/hyp.9251.

Lee M H, Bae D H (2016) Uncertainty Assessment of Climate Change Impacts on Hydrology: A Case Study for the Central Highlands of Vietnam. Procedia Engineering 154: 617-623. https://doi: 10.1016/j.proeng.2016.07.560. Lafaysse M, Hingray B, Mezghani A, Gailhard J, Terray L (2014) Internal variability and model uncertainty components in future hydrometeorological projections: The Alpine Durance basin. Water Resources Research 50(4): p. 3317-3341. https:// doi:10.1002/ 2013WR014897

Maher N, Lehner F, Marotzke J (2020) Quantifying the role of internal variability in the temperature we expect to observe in the coming decades. Environmental Research Letters 15:054014. https://doi.org/10.1088/1748-9326/ab7d02

Nie W, Yuan Y P, Kepner W, Nash M S, Jackson M, Erickson C (2011) Assessing impacts of Land use and 
Landcover changes on hydrology for the upper San Pedro watershed. Journal of Hydrology 407:105-114. https://doi:10.1016/j.jhydrol.2011.07.012.

Nóbrega M T, Collischonn W, Tucci C E M, Paz A R (2011) Uncertainty in climate change impacts on water resources in the Rio Grande Basin, Brazil. Hydrology and Earth System Sciences 15: 585-595. https://doi:10.5194/hess-15-585-2011

Nerantzaki S D, Efstathiou D, Giannakis G V, Kritsotakis M, Grillakis M G, Koutroulis A G, Tsanis I K, Nikolaidis, N P (2019) Climate change impact on the hydrological budget of a large Mediterranean island. Hydrological Science Journal 6 :1190-1203. https://doi.org/10.1080/02626667.2019.1630741

Nerantzaki, S D, Hristopulos, D,T, Nikolaidis, N, P (2020) Estimation of the uncertainty of hydrologic predictions in a karstic Mediterranean watershed. Science of the Total Environment 717: 137131 .https://doi.org/10.1016/j.scitotenv.2020.137131

Pesce M, Critto A, Torresan S, Giubilato E, Pizzol L, Marcomini A (2019) Assessing uncertainty of hydrological and ecological parameters originating from the application of an ensemble of ten global-regional climate model projections in a coastal ecosystem of the lagoon of Venice, Italy. Ecological Engineering 133:121-136. https://doi.org/10.1016/i.ecoleng.2019.04.011

Qin X S, LU Y (2014) Study of climate change impact on flood frequencies_A combined weather generator and hydrological modeling approach. Journal of Hydrometeorology, 15(3):1205-12199.

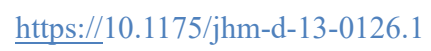

Qi W, Zhang C, Fu G T, Zhou H C, Liu J G (2016) Quantifying Uncertainties in Extreme Flood Predictions under Climate Change for a Medium-Sized Basin in Northeastern China. Journal of Hydrometeorology 17: 3099-3112. https://doi: 10.1175/JHM-D-15-0212.1.

Shi L, Feng P Y, Wan B, Liu D L, Cleverly J, Fang Q X, Yu Q (2020) Projecting potential evapotranspiration change and quantifying its uncertainty under future climate scenarios: A case study in southeastern Australia. Journal of Hydrology 584:124756. https://doi.org/10.1016/j.jhydrol.2020.124756.

Shen M, Chen J, Zhuan M J, Chen H, Xu C Y, Xiong L H (2018) Estimating uncertainty and its temporal variation related to global climate models in quantifying climate change impacts on hydrology. Journal of Hydrology 556: 10-24. https://doi.org/10.1016/j.jhydrol.2017.11.004.

Schindler A, Toreti A, Zampieri M, Scoccimarro E, Gualdi S, Fukutome S F, Xoplaki E, Luterbacher J (2015) On the Internal Variability of Simulated Daily Precipitation, Journal of Climate 28: 3624-3630. http://dx.doi.org/10.1175/JCLI-D-14- 00745.s1.

Steinschneider, S, Wi S, Brown, C (2015) The integrated effects of climate and hydrologic uncertainty on future flood risk assessments. Hydrological Processes, 29(12): 2823-2839. https://doi:10.1002/hyp.10409 Thompson W J D, Barnes, E A, Deser C, Foust W E, Phillips, A S (2015) Quantifying the Role of Internal Climate Variability in Future Climate Trends.Journal of Climate, 28(16): 6443-6456. doi:10.1175/jcli-d-14-00830.1

Vaghef A S, Iravani M, Sauchyn D, Andreichuk Y, Goss G, Faramarzi M (2019) Regionalization and parameterization of a hydrologic model significantly affect the cascade of uncertainty in climate-impact projections. Climate Dynamics 53:2861-2886. https://doi.org/10.1007/s00382-019-04664-w.

Wang Q, XuY P, Xu Y, Wu L, Wang Y F, Han L F (2018) Spatial hydrological responses to land use and land cover changes in atypical catchment of the Yangtze River Delta region. Catena 170:305-315. https://doi.org/10.1016/j.catena.2018.06.022.

Wang Q, Xu Y P, Wang Y F, Zhang Y Q, Xiang J, Xu Y, Wang J (2020) Individual and combined impacts of future land-use and climate conditions on extreme hydrological events in a representative basin of the Yangtze River Delta, China. Atmospheric Research 23:104805. https://doi.org/10.1016/j.atmosres.2019.104805.

Wu H B, Chen (2015) Evaluating uncertainty estimates in distributed hydrological modeling for the Wenjing River 
watershed in China by GLUE, SUFI-2, and ParaSol methods. Ecological Engineering 76:110-121 http://dx.doi.org/10.1016/j.ecoleng.2014.05.014.

820 Wang B, Liu D L, Waters C, Yu Q (2018) Quantifying sources of uncertainty in projected wheat yield changes 821 under climate change in eastern Australia. Climatic Change 151(2): 259273. https://doi.org/10.1007/s10584-018822 2306-Z.

823 Wang F, Huang H G, Fan Y, Li Y P (2020) Robust Subsampling ANOVA Methods for Sensitivity Analysis of

824 Water Resource and Environmental Models. Water Resources Management 34: 3199-3217. 825 https://doi.org/10.1007/s11269-020-02608-2.

826 Xue C, Chen B, ASCE M, Wu H J (2014) Parameter Uncertainty Analysis of Surface Flow and Sediment Yield in 827 the Huolin Basin, China. American Society of Civil Engineers 19: 1224-1236. https://doi: 828 10.1061/(ASCE)HE.1943-5584.0000909.

829 Yen H, Wang XY, Fontane D G, Harmel R D, Arabi M (2014) A framework for propagation of uncertainty 830 contributed by parameterization, input data, model structure, and calibration/validation data in watershed modeling. 831 Environmental Modelling \& Software 54: 211-221. http://dx.doi.org/10.1016/j.envsoft.2014.01.004.

832 Yu B, Li G L, Chen, S F, Lin H (2020) The role of internal variability in climate change projections of North

833 American surface air temperature and temperature extremes in CanESM2 large ensemble simulations. Climate 834 Dynamics 55:869-885. https://doi.org/10.1007/s00382-020-05296-1

835 Yuan S S, Quiring S M, Kalcic M M, Apostel A M, Evenson G R, Kujawa H A (2020) Optimizing climate model 836 selection for hydrological modeling:A case study in the Maumee River basin using the SWAT. Journal of 837 Hydrology 588:125064. https://doi.org/10.1016/j.jhydrol.2020.125064

838 Zhang Y Q, You Q L, Chen C C, Ge J (2016) Impacts of climate change on streamflows under RCP scenarios: A 839 case study in Xin River Basin, China. Atmospheric Research 178-179:521-534.

840 http://dx.doi.org/10.1016/j.atmosres.2016.04.018.

841 Zhang R, Corte-Real J, Moreira M, Kilsby C, Birkinshaw S, Burton A, Fowler H J, Forsythe N, Nunes J P, 842 Sampaio, E, dos Santos F L, Mourato S (2019) Downscaling climate change of water availability, sediment yield 843 and extreme events_ application to a Mediterranean climate basin, International Journal of Climatology 844 39:2947-2963. https://doi: 10.1002/joc.5994.

845 Zhu X P, Zhang C, Qi W, Cai W J, Zhao X H, Wang X F (2018) Multiple Climate Change Scenarios and Runoff 846 Response in Biliu River. Water 10(2):690. https://doi:10.3390/w10060690.

847 Zhang L M, Yuan F, Wang B, Ren L L, Zhao C X, Shi J Y, Liu Y, Jianf S H, Yang X L, Chen T, Liu S Y(2021)

848 Quantifying uncertainty sources in extreme flow projections for three watersheds with different climate features in

849 China. Atmospheric Research 249:105331. https://doi.org/10.1016/j.atmosres

850

851

852

853

854 